\title{
PAHSAs attenuate immune responses and promote $\beta$ cell survival in autoimmune diabetic mice
}

\author{
Ismail Syed, ${ }^{1}$ Maria F. Rubin de Celis, ${ }^{1}$ James F. Mohan, ${ }^{2}$ Pedro M. Moraes-Vieira, ${ }^{1}$ Archana Vijayakumar, ${ }^{1}$ Andrew T. Nelson, ${ }^{3}$ \\ Dionicio Siegel, ${ }^{3}$ Alan Saghatelian, ${ }^{4}$ Diane Mathis, ${ }^{2}$ and Barbara B. Kahn ${ }^{1}$ \\ 'Division of Endocrinology, Diabetes and Metabolism, Department of Medicine, Beth Israel Deaconess Medical Center and Harvard Medical School, Boston, Massachusetts, USA. Division of Immunology, \\ Department of Microbiology and Immunobiology, Harvard Medical School, Boston, Massachusetts, USA. ${ }^{3}$ Skaggs School of Pharmacy and Pharmaceutical Sciences, UCSD, La Jolla, California, USA. ${ }^{4}$ Clayton \\ Foundation Laboratories for Peptide Biology, Helmsley Center for Genomic Medicine, Salk Institute for Biological Studies, La Jolla, California, USA.
}

\begin{abstract}
Palmitic acid esters of hydroxy stearic acids (PAHSAs) are endogenous antidiabetic and antiinflammatory lipids. Here, we show that PAHSAs protect against type 1 diabetes (T1D) and promote $\beta$ cell survival and function. Daily oral PAHSA administration to nonobese diabetic (NOD) mice delayed the onset of T1D and markedly reduced the incidence of T1D, whether PAHSAs were started before or after insulitis was established. PAHSAs reduced T and B cell infiltration and CD4+ and CD8 ${ }^{+}$ T cell activation, while increasing Treg activation in pancreata of NOD mice. PAHSAs promoted $\beta$ cell proliferation in both NOD mice and MIN6 cells and increased the number of $\beta$ cells in NOD mice. PAHSAs attenuated cytokine-induced apoptotic and necrotic $\beta$ cell death and increased $\beta$ cell viability. The mechanism appears to involve a reduction of ER stress and MAPK signaling, since PAHSAs lowered ER stress in NOD mice, suppressed thapsigargin-induced PARP cleavage in human islets, and attenuated ERK1/2 and JNK1/2 activation in MIN6 cells. This appeared to be mediated in part by glucagon-like peptide 1 receptor (GLP-1R) and not the G protein-coupled receptor GPR40. PAHSAs also prevented impairment of glucose-stimulated insulin secretion and improved glucose tolerance in NOD mice. Thus, PAHSAs delayed the onset of T1D and reduced its incidence by attenuating immune responses and exerting direct protective effects on $\beta$ cell survival and function.
\end{abstract}

\section{Introduction}

Type 1 diabetes (T1D) is an autoimmune disease characterized by the destruction of insulin-producing $\beta$ cells, which results in insulin deficiency (1). Both genetic and environmental factors play important roles in the development of islet autoimmunity and subsequent progression to T1D $(2,3)$. Inflammation-induced $\beta$ cell destruction involves islet infiltration by macrophages and $\mathrm{T}$ and $\mathrm{B}$ cells and their production of proinflammatory cytokines and free radicals (4-6). Also, circulating factors such as elevated free fatty acids and high glucose levels promote islet destruction (7-11). Abrogating autoimmunity and increasing $\beta$ cell regeneration, proliferation, and transdifferentiation in the pursuit of a cure for T1D in humans remain major challenges. In addition, although markers to predict T1D have improved, there is still a dire need for novel approaches

\section{Related Commentary: p. 3527}

Authorship note: MFRDC and JFM contributed equally to this work

Conflict of interest: BBK, AS, IS, and PMMV are inventors on the following patents related to the fatty acid hydroxy fatty acid: "Lipids that Increase Insulin Sensitivity and Methods of Using the Same" (patent no. 20180194714); "Fatty Acid Esters of Hydroxy Fatty Acids (FAHFAs) for Use in the Treatment of Type 1 Diabetes" (patent no. 20190151276); and "Methods of Preventing and Treating Inflammatory Bowel Disease with Branched Fatty Acid Esters of Hydroxy Fatty Acids (FAHFAs)" (patent application no. W02017070515A2).

Copyright: @ 2019, American Society for Clinical Investigation.

Submitted: May 23, 2018; Accepted: June 4, 2019; Published: August 5, 2019.

Reference information: J Clin Invest. 2019;129(9):3717-3731.

https://doi.org/10.1172/JCl122445. to halt the progression of the autoimmune response to prevent T1D in islet antibody-positive individuals who have not yet developed overt diabetes. Attempts to prevent T1D have included the study of antigen-specific therapies and systemic immunomodulatory and immunosuppressive agents $(12,13)$. Many of these trials resulted in only transient $\beta$ cell preservation and/or adverse effects due to generalized immune suppression. Immune modulation with compounds such as anti-CD3, CTLA-4 Ig, or anti-CD20 antibodies have proven heterogeneous in their efficacy in new-onset T1D. Islet transplantation has also been pursued, but it has several limitations including a shortage of donors, fibrosis of transplanted islets, and side effects of immunosuppressive agents $(14,15)$. Therefore, agents are needed that are safe, can induce immune tolerance to $\beta$ cells, and can preserve $\beta$ cells and enhance endogenous insulin production in humans at risk for or with overt T1D.

Specific classes of lipids have been suggested to modulate inflammation and diabetes risk in mouse models of T1D. In islets, sulfatide, a glycosphingolipid, and sphingosine-1 phosphate, a sphingolipid, inhibit the production of proinflammatory cytokines (16), attenuate cytokine-induced $\beta$ cell apoptosis (17), and reduce the incidence of diabetes in the nonobese diabetic (NOD) mouse model of autoimmune T1D (18). Other lipids such as omega-3 polyunsaturated fatty acids (PUFAs) and resolvins have antiinflammatory and immunomodulatory effects in a wide array of diseases (e.g., autoimmunity and infection) (19-21). The possibility that omega-3 fatty acids may have antiinflammatory effects in humans is suggested by a study involving healthy adults, which showed that daily fish oil consumption resulted in lower cytokine levels in mononuclear cells (22). This 
led to NOD mouse studies, which showed that dietary omega-3 fatty acids or enhancing endogenous production of omega-3 fatty acids reduces the incidence of T1D by blocking the development of autoimmunity and promoting islet regeneration (23). These lipids also prevent lymphocyte infiltration into regenerated islets in NOD mice (23). Overall, although the results from studies using antiinflammatory lipids in NOD mice are promising, studies in humans who have an increased risk for or established T1D have either been negative or inconclusive, often due to challenges with the experimental design (24). Therefore, identifying antiinflammatory lipids that are safe and effective could lead to new therapeutic agents for T1D. Also, the signaling pathways that mediate the effects of these lipids may provide additional therapeutic targets.

Our laboratory previously described a novel lipid class present in mammals and plants, which we named branched fatty acid esters of hydroxy fatty acids (FAHFAs). These showed beneficial metabolic and antiinflammatory effects (25). More than 24 FAHFA family members have been identified (25-27), and the levels of multiple isomers of at least 1 FAHFA family member, palmitic acid hydroxy stearic acids (PAHSAs), are lower in the serum and adipose tissue of insulin-resistant humans (25). PAHSAs directly augment glucose-stimulated insulin secretion (GSIS) from human pancreatic islets and glucagon-like peptide 1 (GLP-1) secretion from enteroendocrine cells (25). Furthermore, PAHSAs have antiinflammatory effects that include attenuation of proinflammatory cytokine production by adipose tissue macrophages in insulin-resistant obese mice and a reduction of LPS-induced dendritic cell activation and the subsequent proinflammatory cytokine production in vitro $(25,26)$. PAHSAs also have antiinflammatory effects in the gut and protect mice from experimental colitis by decreasing colonic inflammation (28). Some of the effects in immune cells appear to be mediated by the $G$ protein-coupled receptor GPR120 (28). Because PAHSAs have direct effects on islet $\beta$ cells and immune cells $(25,26,28)$, we hypothesized that PAHSAs may attenuate pathways involved in immune-mediated $\beta$ cell destruction and reduce the incidence of T1D. Here, we report that chronic oral PAHSA treatment delayed the onset and decreased the incidence of T1D in NOD mice by attenuating islet inflammation, increasing $\beta$ cell proliferation and numbers, and exerting direct protective effects that increased $\beta$ cell survival and function through mechanisms involving ER stress reduction. This appeared to be mediated in part by glucagon-like peptide 1 receptor (GLP-1R) and not by GPR40. The fact that the same PAHSA isomers are present at similar concentrations in humans and mice (25) may facilitate translating dosing regimens from mice to humans, which has been a challenge in studies of other potential therapeutic agents (24). Thus, PAHSAs could potentially be used as therapeutic agents to treat T1D, and the pathways they engage could provide additional new targets for $\beta$ cell preservation in T1D.

\section{Results}

Chronic PAHSA treatment delays the onset and reduces the incidence of diabetes in NOD mice. We tested whether chronic 5- and 9-PAHSA treatment delays the onset and attenuates the incidence of T1D in female NOD mice. Treatment in mice was started either at 4 weeks of age (early intervention; protocol shown in Supplemental Figure $1 \mathrm{~A}$ ), before insulitis appears, or at 13 weeks of age (late inter- vention; protocol shown in Supplemental Figure 1B), when insulitis is established (29). We found that serum 5- and 9-PAHSA levels were increased 4 - to 5 -fold after 6 weeks of PAHSA treatment compared with levels in vehicle-treated NOD mice (Figure 1A). To determine how rapidly serum PAHSA levels rise with daily oral gavage, we measured levels in chow-fed $\mathrm{C} 57 \mathrm{Bl} / 6 \mathrm{~J}$ mice at earlier time points after PAHSA administration. Following oral gavage of 5- and 9-PAHSA, serum 9-PAHSA levels were increased by approximately 1.7-fold after 1 week of treatment and by approximately 2.9fold after 2 weeks of treatment, and serum 5-PAHSA levels were increased by approximately 2.7 -fold after 1 week of treatment and by approximately 4 -fold after 2 weeks of treatment compared with baseline levels (Supplemental Figure 1C). These data indicate that serum PAHSA levels were increased as early as after 1 week of treatment, increased further after 2 weeks of treatment, and remained stably increased until at least week 6 of treatment (Figure 1A).

Chronic 5- and 9-PAHSA treatment in NOD mice had no effect on body weight (Figure 1B and Supplemental Figure 1D) or tissue weights (Supplemental Figure 1E). However, PAHSA treatment starting at 4 weeks of age delayed T1D onset by 3 weeks, reduced the cumulative T1D incidence from $82 \%$ in the vehicle-treated mice to $35 \%$ (Figure 1C), and improved the survival rate from $22 \%$ for vehicle-treated mice to $78 \%$ for PAHSA-treated mice (Supplemental Figure 1F). Initiating PAHSA treatment in mice at 13 weeks of age also reduced the cumulative diabetes incidence from $90 \%$ in vehicle-treated mice to $40 \%$ in PAHSA-treated mice (Figure 1D) and improved the survival rate from $38 \%$ for vehicle-treated mice to $92 \%$ for PAHSA-treated mice (Supplemental Figure $1 \mathrm{~F}$ ). The late intervention study was terminated at 26 weeks of age, since 8 of 13 of the vehicle-treated mice died, 4 of the remaining vehicle-treated diabetic mice were sick, and only 1 mouse was not diabetic. We were able to continue the early treatment study longer, out to 30 weeks of age, because of better survival rates (Supplemental Figure 1F). The divergence in diabetes incidence began at 15 weeks of age in the mice that received early treatment (Figure 1C) and at 16 weeks of age in those that received later treatment (Figure 1D). Since we reported that PAHSAs directly enhance GSIS in human islets ex vivo and in mice in vivo $(25,30)$, we tested whether chronic PAHSA treatment in NOD mice enhances GSIS, which could contribute to the maintenance of normal glycemia. Figure $1 \mathrm{E}$ shows that 5 - and 9-PAHSA treatment starting from 4 weeks of age increased serum insulin levels in mice fed ad libitum compared with levels in vehicle-treated mice at 10 weeks of age ( 6 weeks of treatment), and the effect was even greater at 17 weeks of age (13 weeks of treatment). Only nondiabetic mice were included in the study. To determine whether the increase in insulin levels was due to increased GLP1 levels, we measured serum total GLP-1 levels in ad libitum-fed vehicle- and PAHSA-treated NOD mice. Total GLP-1 levels were unchanged with PAHSA treatment compared with vehicle treatment, whether we included or excluded the diabetic mice (Figure $1 F)$. Five of the 6 diabetic mice had higher GLP-1 levels than did nondiabetic mice. Furthermore, PAHSA treatment potentiated GSIS (Figure 1G), which resulted in lower glycemia after glucose gavage (Figure $1 \mathrm{H}$ ) compared with vehicle treatment. In addition, PAHSA-treated NOD mice were more glucose tolerant than were vehicle-treated mice, as evidenced by lower glucose excursion during the oral glucose tolerance test (OGTT) and a reduced AUC 
A
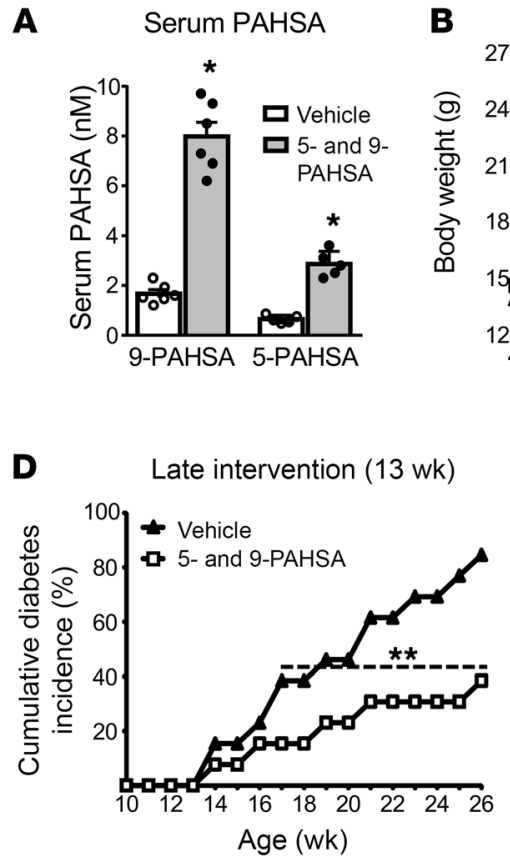

G

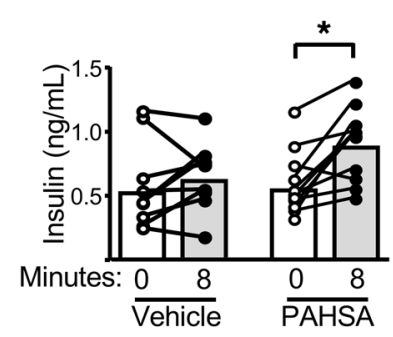

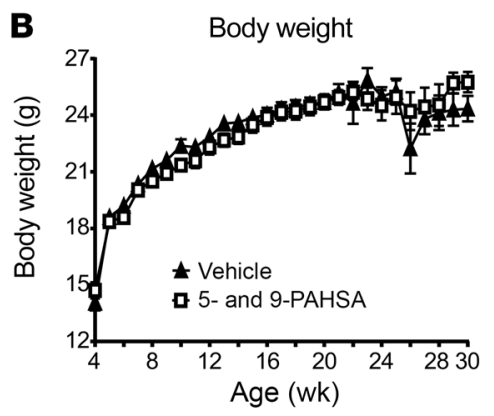

E Ad libitum serum insulin $10 \mathrm{wk}$ of age $17 \mathrm{wk}$ of age

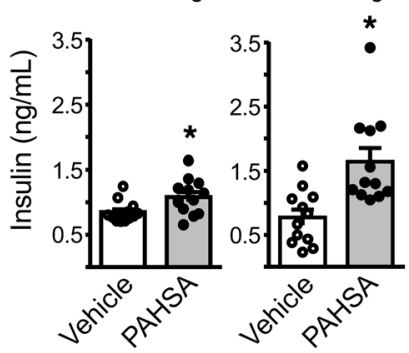

H

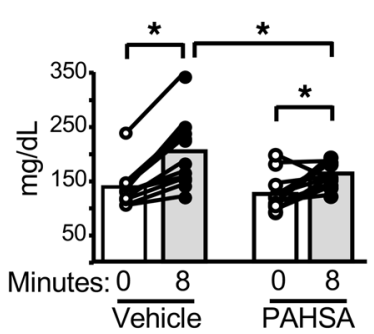

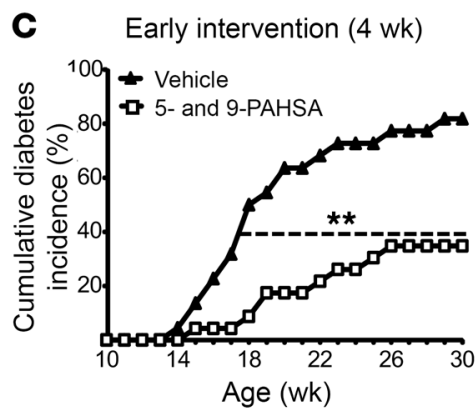

F

Ad libitum serum total GLP-1 Including diabetic Excluding diabetic

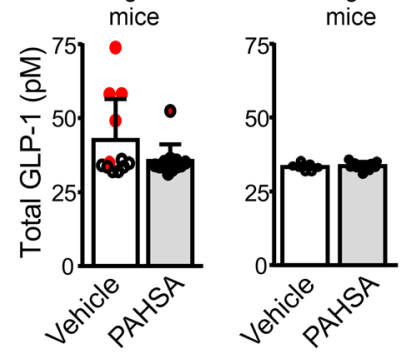

I

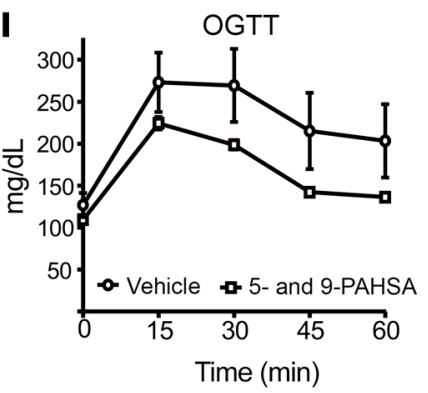

AUC

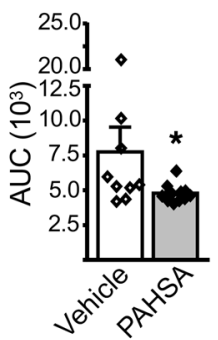

Figure 1. Chronic PAHSA treatment delays the onset and reduces the incidence of diabetes in NOD mice. Female NOD mice were treated with vehicle and 5 - and 9-PAHSA (each $15 \mathrm{mg} / \mathrm{kg} \mathrm{BE/day).} \mathrm{(A)} \mathrm{Serum} \mathrm{5-} \mathrm{and} \mathrm{9-PAHSA} \mathrm{levels} \mathrm{at} 6$ weeks of PAHSA treatment. $n=5-6 /$ group. ${ }^{*} P<0.05$ versus vehicle. Data indicate the mean \pm SEM. Differences between groups were assessed by 2-tailed Student's $t$ test. (B) Body weight over 26 weeks of treatment, starting from 4 weeks of age. $n=22-23$ /group. (C) Cumulative diabetes incidence in NOD mice treated with PAHSAs for 26 weeks starting at 4 weeks of age $\left(n=22-23 /\right.$ group). ${ }^{* *} P<0.001$ versus vehicle. Differences between groups were assessed by log-rank test $(z=4.12)$. (D) Cumulative diabetes incidence in NOD mice treated with PAHSAs for 13 weeks starting at 13 weeks of age ( $n=13 /$ group). ${ }^{* *} P<0.001$ versus vehicle. Differences between groups were assessed by log-rank test ( $\left.z=3.51\right)$. (E) Serum insulin levels at 6 and 13 weeks of PAHSA treatment in ad libitum-fed NOD mice from the early intervention group ( $n=14-12 /$ group). ${ }^{*} P<0.05$ versus vehicle. Data indicate the mean \pm SEM. Differences between groups were assessed by 2-tailed Student's $t$ test. (F) Serum total GLP-1 levels at 15 weeks of PAHSA treatment ( $n=12$ /group). The red data points represent diabetic mice in the vehicle- and PAHSA-treated groups. Glucose-stimulated insulin secretion (CSIS) (C) and glycemia during GSIS (H) at 9 weeks of PAHSA treatment ( $n=10-11 /$ group). ${ }^{*} P<0.05$ versus the $t_{0}$ time point within the group. (I) Oral glucose tolerance test (OGTT) at 11 weeks of PAHSA treatment. $n=9-11$ /group. ${ }^{*} P<0.05$ versus vehicle. For $\mathbf{G}-\mathbf{I}$, data indicate the mean $\pm \mathrm{SEM}$. Differences between groups were assessed by a repeated-measures ANOVA with a Newman-Keuls multiple-comparisons test. For E-I, only nondiabetic mice were included in the study. For $\mathbf{G}$, the only PAHSA-treated mouse that did not show an increase in insulin secretion in response to glucose at 13 weeks of age subsequently became diabetic at 17 weeks of age.

(Figure 1I). These data demonstrate that PAHSAs potentiate GSIS and improve glucose tolerance in NOD mice, effects that may have resulted from increased $\beta$ cell survival and proliferation (see below). In sum, PAHSA treatment protected against the development of T1D in mice with incipient and established insulitis. In addition, chronic 5- and 9-PAHSA treatment was safe, was not associated with liver or renal toxicity, as measured by serum alanine amino transferase and creatinine levels, and did not alter liver triglyceride content (Supplemental Figure 1G).

Chronic 5- and 9-PAHSA treatment has minimal effects on insulitis but reduces pancreatic $T$ cell activation in NOD mice. To determine the mechanisms by which PAHSAs attenuate T1D in
NOD mice, we examined the effects on insulitis and inflammatory immune markers. PAHSA treatment for 6 weeks, starting in 4-week-old mice, had a tendency to lower the insulitis score $(P=$ 0.06) compared with vehicle-treated mice (Figure 2A). PAHSAs had a subtle effect on the number of clear islets (no infiltration: vehicle $50 \% \pm 6 \%$ vs. PAHSA $65 \% \pm 5 \%$ of islets; $P<0.05$ ) and on the overall severity of insulitis (destructive intra-insulitis: vehicle $23 \% \pm 5 \%$ vs. PAHSA $13 \% \pm 2 \%$; $P<0.05$ ) (Figure 2 B). Flow cytometric analysis of the pancreatic infiltrates from mice treated for 7 weeks with PAHSAs (11 weeks of age) showed a similar number of leukocytes $\left(\mathrm{CD} 45^{+}\right.$cells) compared with vehicle-treated mice (Figure $2 \mathrm{C}$ ). But at 15 weeks of age, after 11 weeks of treatment, leu- 
A

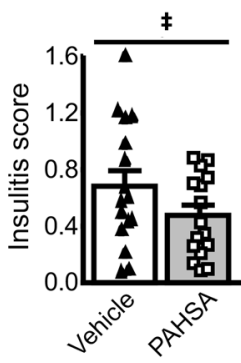

B

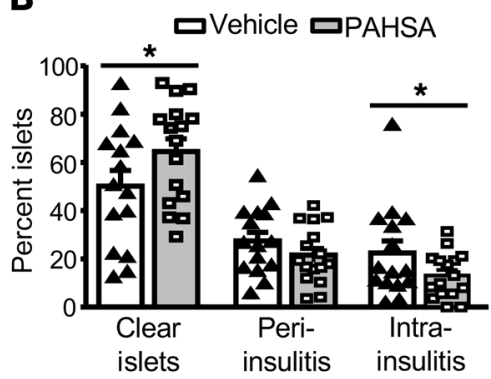

C

11 wk of age $\quad 15$ wk of age

(7 wk of treatment) (11 wk of treatment)

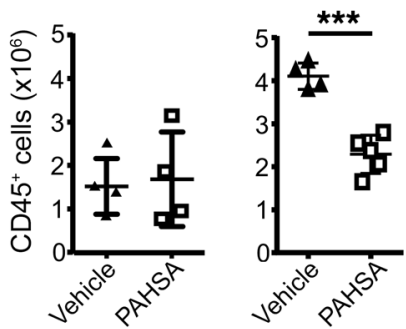

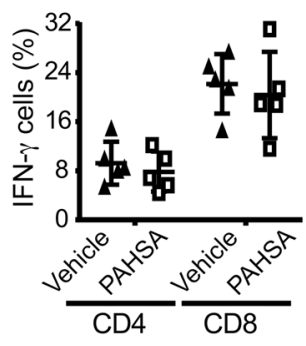
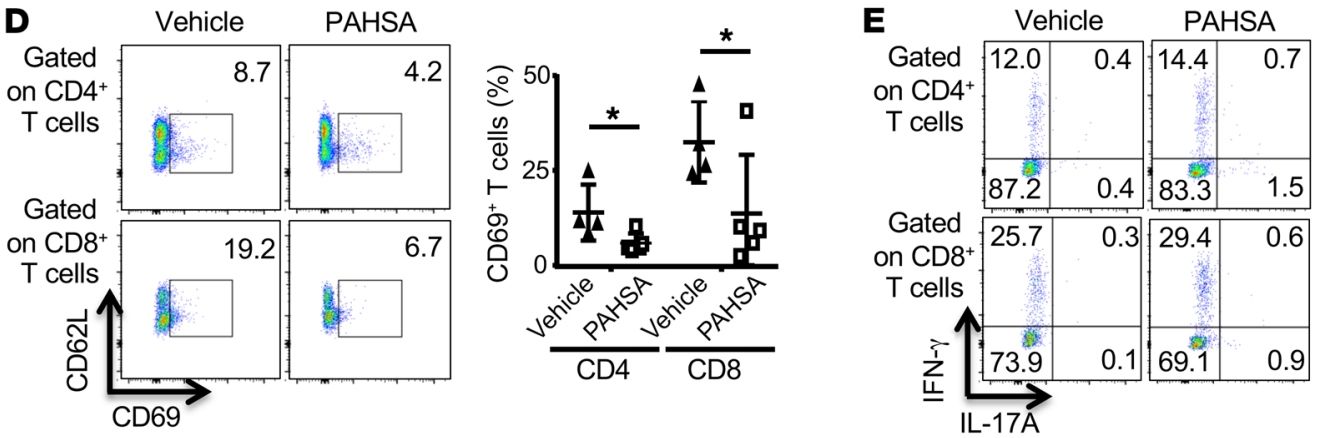

$\mathbf{F}$
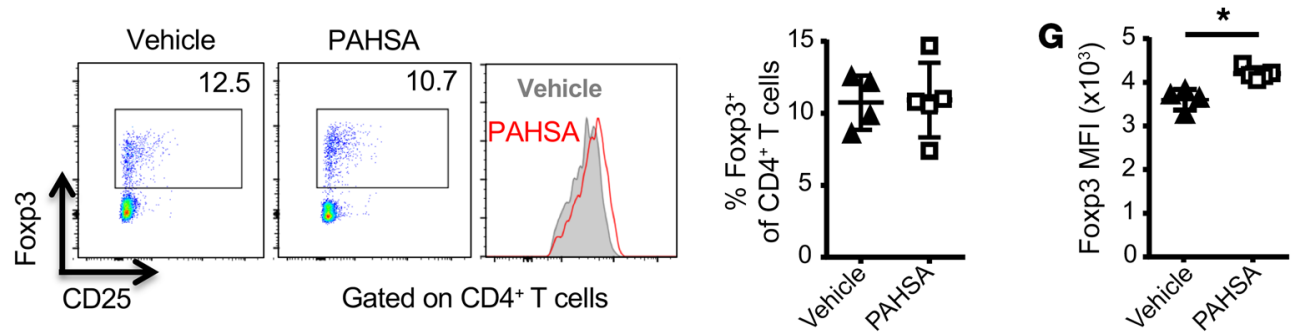

Figure 2. Chronic 5- and 9-PAHSA treatment has a minimal effect on insulitis but reduces pancreatic T cell activation in NOD mice. Female NOD mice were treated with vehicle or 5- and 9-PAHSAs for 6 weeks starting at 4 weeks of age. (A) Insulitis score and (B) percentage of islets that were clear or had peri-insulitis or intra-insulitis. Islets (50-100/mouse) were scored for insulitis. $n=16$-17/group $(\mathbf{A}$ and $\mathbf{B}) .{ }^{*} P<0.05$ versus vehicle-treated mice; ${ }^{\ddagger} P=$ 0.06 versus vehicle-treated mice. (C) Total number of $\mathrm{CD} 45^{+}$cells per gram of pancreata from mice treated with 5 - and 9 -PAHSAs or vehicle for 7 weeks (11 weeks of age) or 11 weeks (15 weeks of age). $n=4-5 /$ group. ${ }^{* * * *} P<0.0001$ versus vehicle-treated mice. Percentage of CD69+ $T$ cells (D) and IFN- $\gamma^{+} T$ cells $(E)$ in gated $C D 4^{+}$and $C D 8^{+} T$ cell population in pancreata from mice treated with 5 - and 9-PAHSAs or vehicle for 11 weeks. Representative cytofluorometric dot plots and summary data are shown $(n=4-5){ }^{*} P<0.05$ versus vehicle-treated mice. (F) Proportions of Foxp $3^{+}$cells within the CD4 ${ }^{+} T$ cell population in pancreata from 5- and 9-PAHSA- or vehicle-treated mice. Representative cytofluorometric dot plots and summary data are shown $(n=4-5)$. (G) Foxp3 ${ }^{+}$ MFI in pancreata from 5- and 9-PAHSA- or vehicle-treated mice $(n=4-5) .{ }^{*} P<0.05$ versus vehicle-treated mice. Data indicate the mean \pm SEM. Differences between groups were assessed by 2-tailed Student's $t$ test.

kocyte infiltration was increased by 2-fold in the vehicle-treated mice, with no increase observed in PAHSA-treated mice (Figure $2 \mathrm{C}$ ). We detected a reduction in the total number of pancreaticinfiltrating immune cells in PAHSA-treated mice for nearly all cell populations examined, but the fractional representation of these immune cells within the bulk $\mathrm{CD} 45^{+}$compartment appeared to be unaltered in the PAHSA- versus vehicle-treated mice (Supplemental Figure 2, A and B). However, the percentage of B cells was significantly lower with PAHSA treatment compared with the percentage seen with vehicle treatment (Supplemental Figure 2B).

Furthermore, PAHSA treatment for 11 weeks resulted in a concomitant reduction in T cell activation as measured by CD69 expression (Figure 2D, gating strategy). The population of $\mathrm{T}$ cells expressing IFN- $\gamma$ (Figure 2E, gating strategy), programmed cell death 1 (PD-1) (Supplemental Figure 2C), and IL-10 (data not shown) was unaltered with PAHSA treatment. In addition, PAHSA treatment did not alter the percentage of Foxp $3^{+} \mathrm{CD} 4^{+} \mathrm{T}$ cells (Tregs) (Figure 2F, gating strategy) or expression of CD25 on Tregs (Supplemental Figure 2D), but increased Foxp3 protein levels in pancreatic Tregs (Figure 2G). Furthermore, the MFI of CD86 and the percentage of MHC-II ${ }^{+}$cells (Supplemental Figure 2E) were unaltered with PAHSA treatment. Together, these data suggest that chronic PAHSA treatment delays the onset of T1D and reduces its incidence in NOD mice by attenuating leukocyte infiltration and $\mathrm{T}$ cell activation.

PAHSA treatment increases islet $\beta$ cell proliferation under cytokine stress. We next determined whether PAHSAs increase pancreatic $\beta$ cell proliferation during cytokine insult. PAHSA treatment of NOD mice for 7 weeks starting from 4 weeks of age attenuated inflammation, resulting in the maintenance of islet architecture and less islet expansion (Figure 3A). Vehicle-treated mice showed 
A

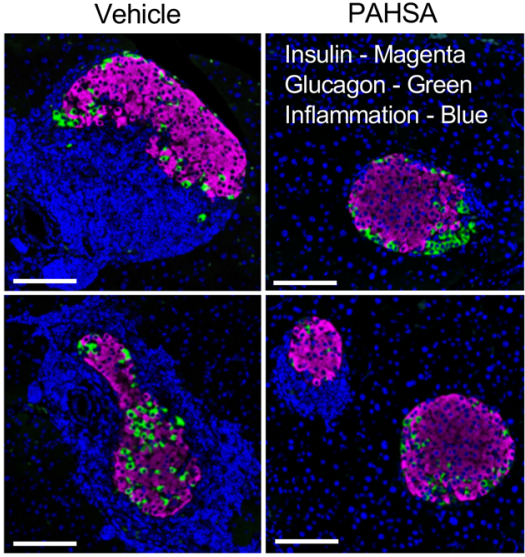

D
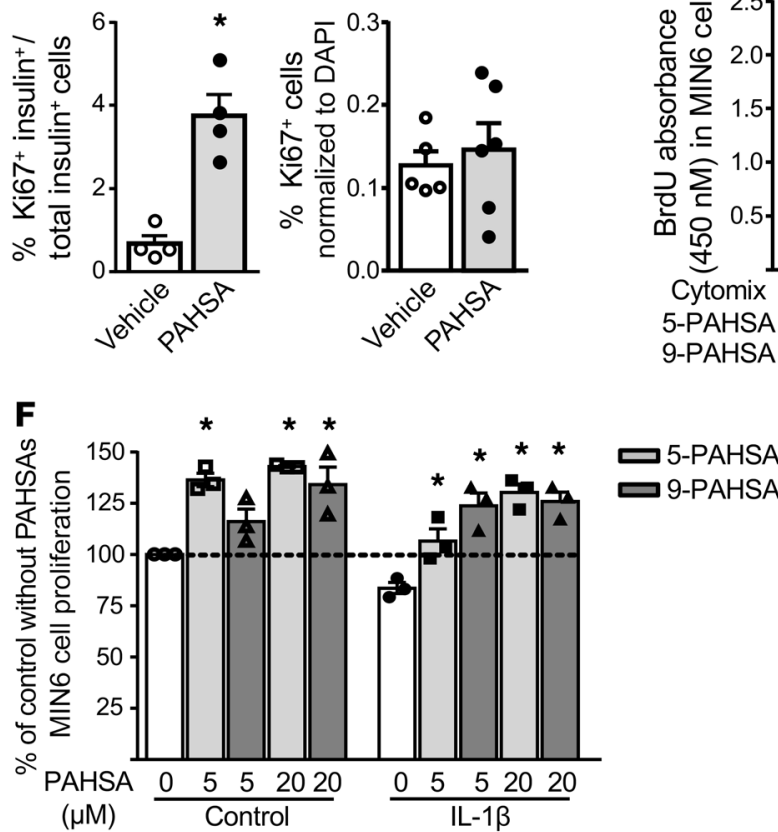

B

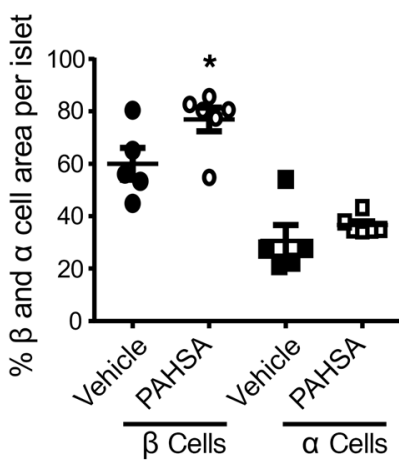

E

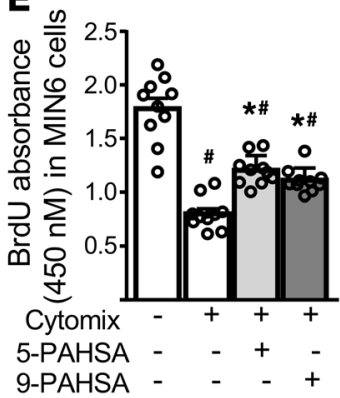

C
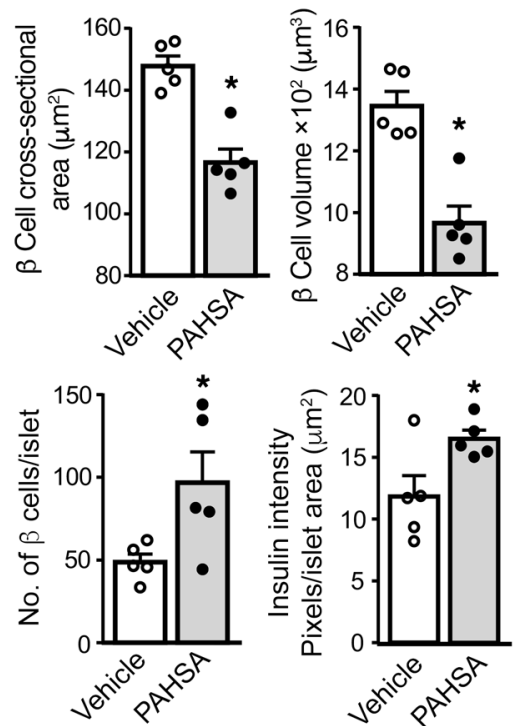

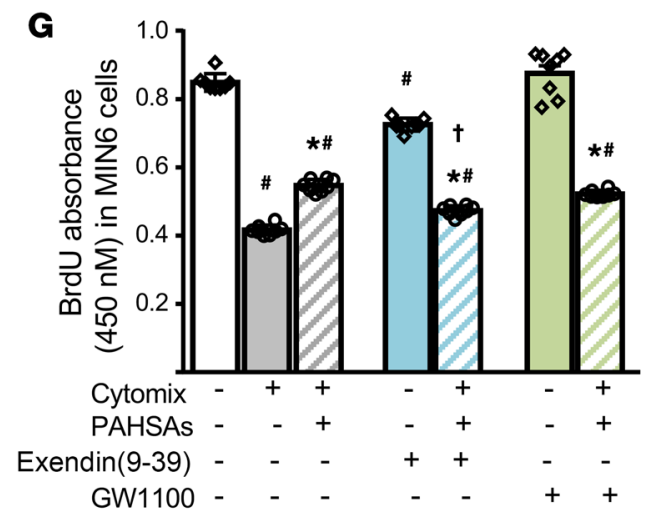

Figure 3. PAHSA treatment increases islet $\boldsymbol{\beta}$ cell proliferation under cytokine stress. Female NOD mice were treated with vehicle or 5 - and 9 -PAHSAs for 7 weeks starting at 4 weeks of age. None of the vehicle- or PAHSA-treated mice at this age were diabetic and all had glycemia levels below 150 mg/dL following ad libitum feeding. (A) Islet inflammation and architecture. Scale bars: $100 \mu \mathrm{m}$. (B) Percentage of $\beta$ cell and $\alpha$ cell area per islet. (C) $\beta$ Cell cross-sectional area, $\beta$ cell volume, $\beta$ cell numbers, and insulin intensity. (D) $\beta$ Cell proliferation and liver proliferation were determined by Ki67 staining ( $n=4-7 /$ group). ${ }^{*} P<0.05$ versus vehicle-treated mice. For B-D, data indicate the mean \pm SEM. Differences between groups were assessed by 2-tailed Student's $t$ test. (E) MIN6 cells were treated with cytomix ( $5 \mathrm{ng} / \mathrm{mL}$ TNF- $\alpha$ plus $5 \mathrm{ng} / \mathrm{mL}$ IL-1 $\beta$ plus $10 \mathrm{ng} / \mathrm{mL}$ IFN- $\gamma$ ) in the presence of 5- or 9-PAHSA (20 $\mu \mathrm{m}$ each) for 48 hours, and $\beta$ cell proliferation was measured by BrdU incorporation ( $n=10$, for 8 wells/condition). ${ }^{*} P<0.05$ versus control with no PAHSAs; ${ }^{*} P<0.05$ versus cytomix alone and control alone. (F) Cell tracer-tracked MIN6 cells were treated with either diluent or IL-1 $\beta$ ( $10 \mathrm{ng} / \mathrm{mL}$ ) for 48 hours in the presence of 5 - or 9 -PAHSA ( 5 and $20 \mu \mathrm{M})$. The percentage of MIN6 cell proliferation versus control was measured by flow cytometry ( $n=3$ wells/condition). ${ }^{*} P<0.05$ versus control alone and IL-1 $\beta$ alone. Studies in $\mathbf{E}$ and F were performed twice. (G) MIN6 cells were treated with cytomix ( $5 \mathrm{ng} / \mathrm{mL}$ TNF- $\alpha$ plus $5 \mathrm{ng} / \mathrm{mL}$ IL- $1 \beta \mathrm{plus} 10 \mathrm{ng} / \mathrm{mL}$ IFN- $\gamma$ ) in the presence of 5 - and $9-\mathrm{PAHSAs}$ (20 $\mu \mathrm{M}$ each), exendin(9-39) (10 nM), and GW1100 (10 $\mu \mathrm{M})$ for 24 hours, and MIN6 cell proliferation was measured by BrdU incorporation into cells ( $n=8$ for 12 wells/condition). ${ }^{\# P}<0.05$ versus control alone; ${ }^{*} P<0.05$ versus cytomix alone, and control alone; ${ }^{\dagger} P<0.05$ versus cytomix with $\mathrm{PAHSAs}$. Data indicate the mean \pm SEM. Differences between groups were assessed by ANOVA with Bonferroni's multiple comparisons test.

enlargement of islets and loss of normal islet architecture due to immune cell infiltration. We measured the relative $\beta$ cell and $\alpha$ cell area per islet but not the total $\beta$ cell mass. PAHSA-treated mice had a larger $\beta$ cell area relative to the total islet area and a tendency toward a larger relative $\alpha$ cell area compared with vehicletreated mice (Figure 3B). This was largely due to reduced immune cell infiltration. Furthermore, with chronic PAHSA treatment, the mean $\beta$ cell cross-sectional area was reduced by $21 \%$, and the $\beta$ cell volume was reduced by $28 \%$ (Figure $3 \mathrm{C}$ ) compared with what we observed in the vehicle-treated mice. The fact that the $\beta$ cell area per islet was increased indicates that PAHSA-treated animals had more $\beta$ cells per islet (Figure $3 \mathrm{C}$ ). In addition, the insulin intensity 
A

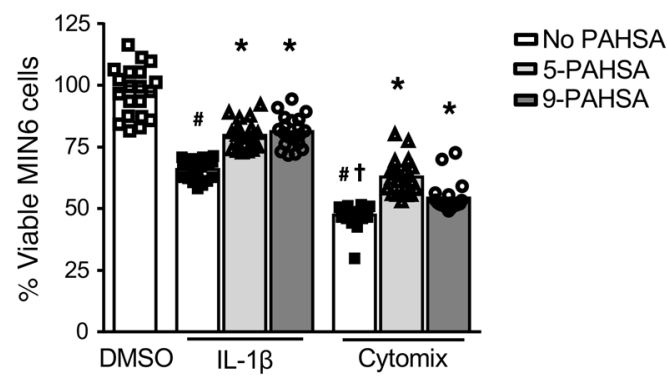

C
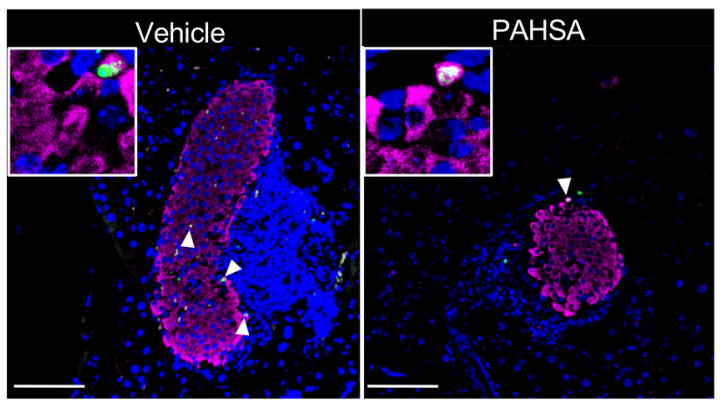

B
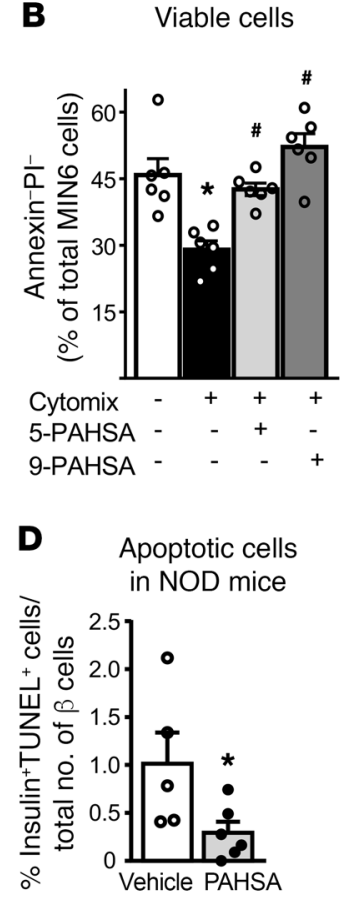

Late apoptotic cells

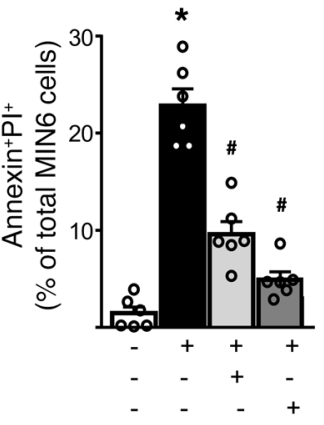

Necrotic cells

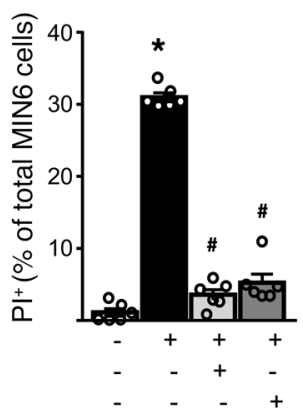

E

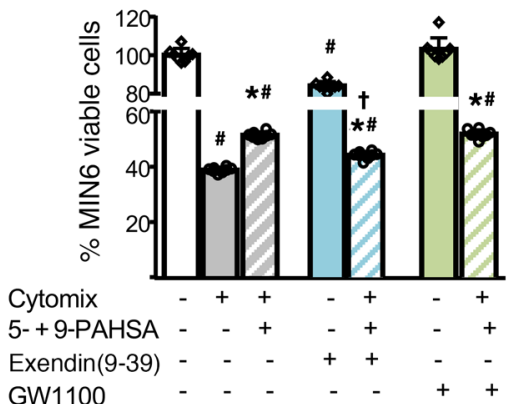

Figure 4. PAHSA treatment increases islet $\beta$ cell viability and attenuates cytokine-induced $\beta$ cell death. (A) MIN6 cells were treated with either diluent or IL-1 $\beta(10 \mathrm{ng} / \mathrm{mL})$ or cytomix (TNF- $\alpha$ plus IL-1 $\beta$ plus IFN- $\gamma ; 10 \mathrm{ng} / \mathrm{mL}$ each) for 40 hours in the presence of 5- or 9-PAHSA (5 $\mu$ M each). The percentage of viable $\beta$ cells was measured by MTT assay and calculated as the percentage of DMSO control ( $n=24$ wells/condition). ${ }^{*} P<0.05$ versus control DMSO; ${ }^{\dagger} P<$ 0.05 versus control DMSO and IL-1 $\beta ;{ }^{*} P<0.05$ versus the respective cytokine treatment. Data indicate the mean $\pm \mathrm{SEM}$. Differences between groups were assessed by ANOVA with Newman-Keuls multiple comparisons test. (B) MIN6 cells were treated with cytomix in the presence of 5- or 9-PAHSA (20 $\mu$ M each) for 24 hours and stained with annexin $\mathrm{V}$ and PI. The effect of cytomix and PAHSAs on viability is expressed as a percentage of the total number of cells sorted ( $n=6$ wells/condition). ${ }^{*} P<0.05$ versus control; ${ }^{*} P<0.05$ versus cytomix. Data indicate the mean \pm SEM. Differences between groups were assessed by ANOVA with Bonferroni's multiple comparisons test. (C) Representative images of apoptotic cells in NOD mice treated for 15 weeks with vehicle or PAHSA starting at 4 weeks of age. Scale bars: $100 \mu \mathrm{m}$. Original magnification, $\times 256$ (insets). (D) Female NOD mice were treated with vehicle or PAHSA for 15 weeks starting at 4 weeks of age, and the number of apoptotic cells was determined by TUNEL staining $\left(n=5-6 /\right.$ group). ${ }^{*} P<0.05$ versus vehicle-treated mice. Data represent the mean \pm SEM. Differences between groups were assessed by 2-tailed Student's $t$ test. (E) MIN6 cells were treated with either diluent or cytomix for 24 hours in the presence of 5 - and 9-PAHSAs ( $20 \mu \mathrm{M}$ each), exendin(9-39) (10 nM), and GW1100 (10 $\mu$ M). The percentage of viable $\beta$ cells was measured by MTT assay and calculated as the percentage of DMSO control $\left(n=8\right.$, for 12 wells/condition. ${ }^{\#} P<0.05$ versus control; ${ }^{*} P<$ 0.05 versus cytomix alone and control alone; ${ }^{\dagger} P<0.05$ versus cytomix with PAHSA treatment. Data indicate the mean \pm SEM. Differences between groups were assessed by ANOVA with Bonferroni's multiple comparisons test.

per islet area appeared to be increased in PAHSA-treated NOD mice compared with vehicle-treated mice, indicating more insulin content per islet (Figure 3C and see Supplemental Figure 3A for a diagram of the region of interest [ROI]). In PAHSA-treated nondiabetic NOD mice, $\beta$ cell proliferation appeared to be increased, since the islets in these mice had an increased percentage of cells double-positive for insulin and Ki67 compared with vehicle-treated nondiabetic NOD mice (Figure 3D). This finding suggests that PAHSAs promote $\beta$ cell proliferation in nondiabetic NOD mice with normal glycemia and that hyperglycemia is not necessary to promote $\beta$ cell proliferation. However, the proliferation could be a response to insulitis in these mice. This was not a generalized proliferative effect, since liver from PAHSA-treated mice did not show an increase in Ki67 $7^{+}$cells (Figure 3D). Thus, the increase in $\beta$ cell numbers and insulin intensity per islet area (Figure 3C) may have resulted from an increase in $\beta$ cell proliferation (Figure 3D) and/or a decrease in $\beta$ cell death (Figure 4, A-E) in PAHSA-treated NOD mice.
To further substantiate the proliferative effects of PAHSAs on $\beta$ cells, we measured BrdU incorporation into MIN6 clonal $\beta$ cells subjected to cytokine stress in the presence or absence of 5or 9-PAHSA. Inflammatory cytokines such as IL-1 $\beta$, TNF- $\alpha$, and INF- $\gamma$ induce $\beta$ cell death in vitro. Cytomix (mixture of the cytokines IL-1 $\beta$, TNF- $\beta$, and IFN- $\gamma$ ) treatment reduced BrdU incorporation into MIN 6 cells by $56 \%$, and this was partially blocked by either 5-PAHSA or 9-PAHSA (Figure 3E and Supplemental Figure 3B). In separate studies, MIN6 cell proliferation was tracked with CellTrace Violet in the presence of PAHSAs with or without IL-1 $1 \beta$. IL-1 $\beta$ treatment attenuated MIN6 cell proliferation, and both 5and 9-PAHSA augmented MIN6 cell proliferation in control and IL-1 $\beta$-treated cells (Figure 3F). Together, these data indicate that both 5-PAHSA and 9-PAHSA enhance $\beta$ cell proliferation in vitro and in vivo during proinflammatory cytokine stress.

PAHSAs enhance GSIS and GLP-1 secretion, and the effects on insulin secretion are mediated through GPR $40(25,30)$. Since GLP-1R agonists promote $\beta$ cell proliferation (31), and studies 
A

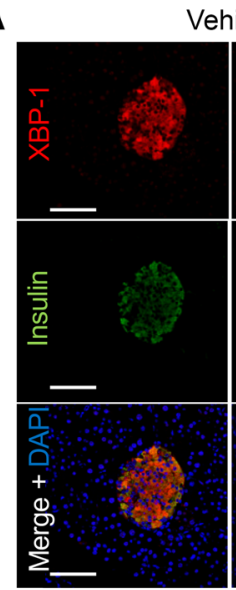

Vehicle
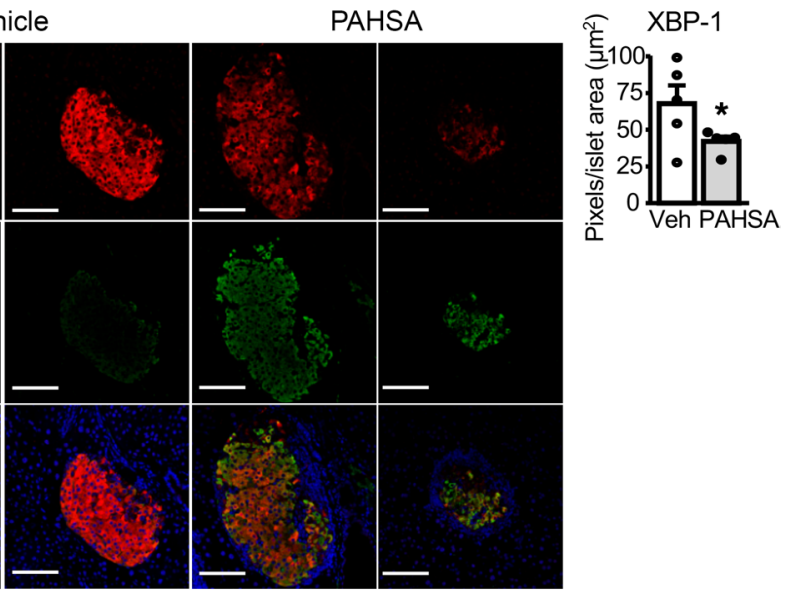

B
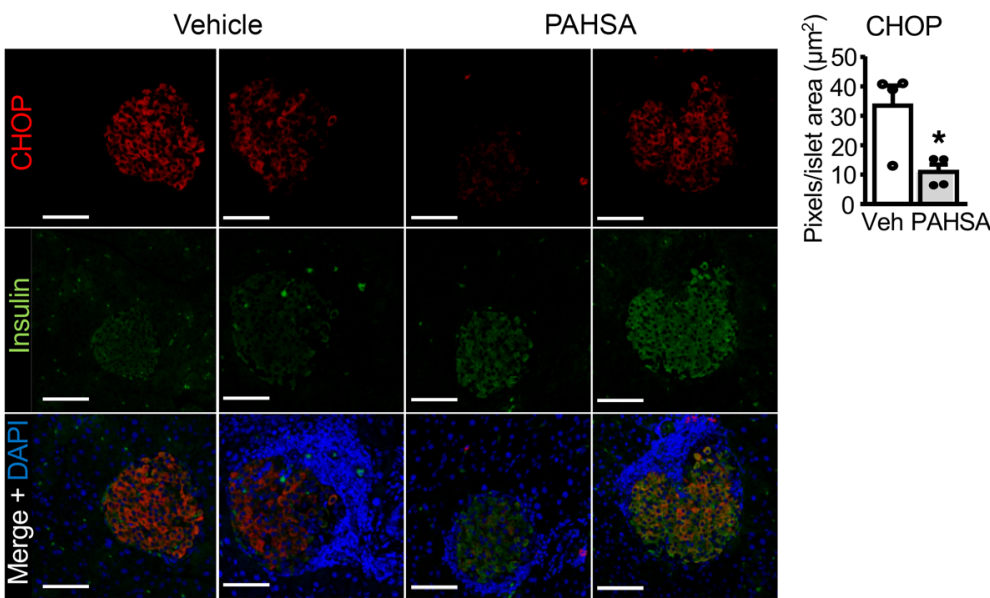

C
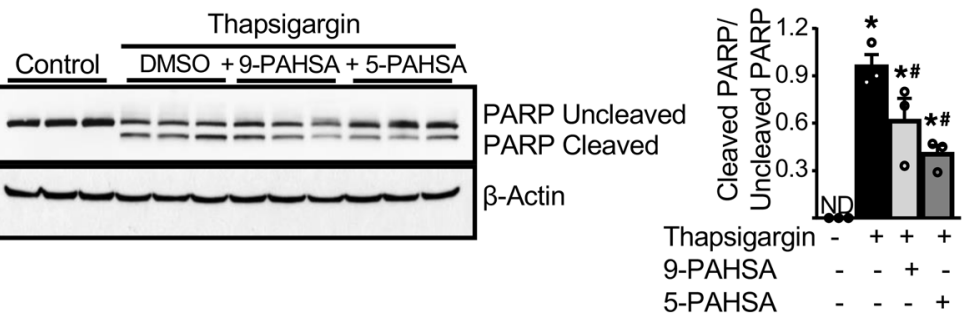

D

Thapsigargin

Control DMSO +5-PAHSA + 9-PAHSA

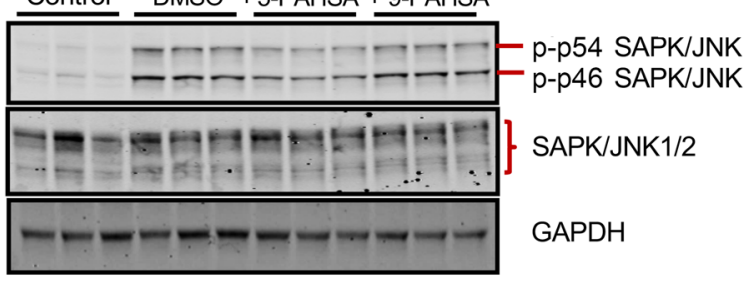

E $5.5 \mathrm{mM}$ Glucose $25 \mathrm{mM}$ Glucose

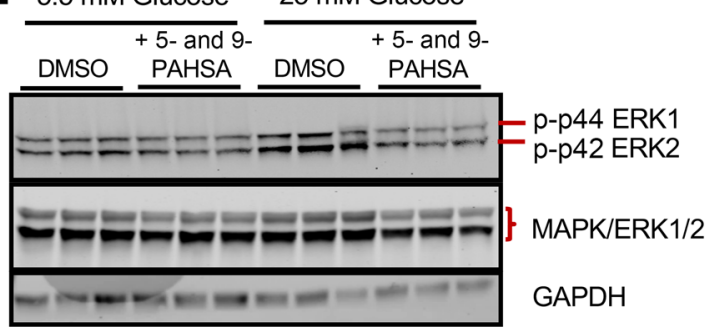
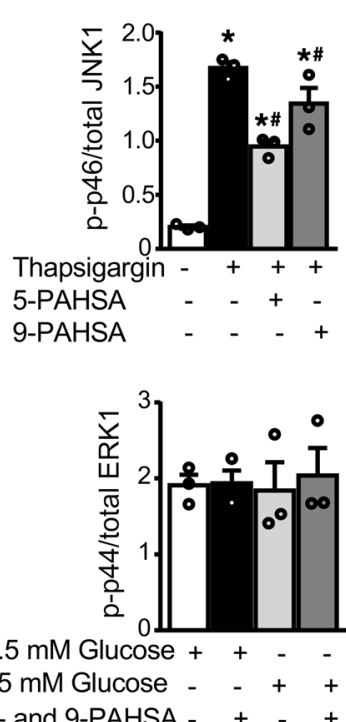

Figure 5. PAHSA treatment attenuates $\beta$ cell death by inhibiting ER stress. Female NOD mice were treated with vehicle or 5- and 9-PAHSA for 7 weeks starting at 4 weeks of age, and XBP-1 (A) and CHOP (B) intensities were determined by immunohistochemical analyses ( $n=4-5$ mice/group). ${ }^{*} P<0.05$ versus vehicle-treated mice. Scale bars: $100 \mu \mathrm{m}$. Data indicate the mean \pm SEM. Differences between groups were assessed by 2 -tailed Student's $t$ test. (C) Human islets from nondiabetic donors were treated with thapsigargin $(2 \mu \mathrm{mol} / \mathrm{L})$ for 6 hours in the presence of 5-PAHSA or 9-PAHSA ( $20 \mu \mathrm{M}$ each). Western blot analysis was performed with the cell lysates to determine PARP cleavage ( $n=3$ wells/condition, and each treatment condition had 250 islets in triplicate). Bar graphs show the densitometric analysis of the ratio of cleaved PARP to uncleaved PARP for each condition. ${ }^{*} P<0.05$ versus control DMSO; ${ }^{\#} P<0.05$ versus thapsigargin. ND, not determined. MIN6 cells were treated with thapsigargin $(0.5 \mu \mathrm{M})$ for 6 hours (D) or physiological glucose $(5.5 \mathrm{mM})$ or high glucose (25 mM) for 24 hours (E) in the presence of 5- and/ or 9-PAHSA ( $20 \mu \mathrm{M}$ each). All conditions contained DMSO. Western blot analysis was performed to determine phosphorylation of JNK1/2 and ERK1/2 ( $n$ $=3$ wells/condition). Bar graphs show the densitometric analysis of the ratio of $p$-JNK1 or $p$-JNK2 to the corresponding total JNK1 or JNK2 (D) and p-ERK1 or p-ERK2 to the corresponding total ERK1 or ERK2 (E) for each condition. SAPK, stress-activated protein kinase. ${ }^{*} P<0.05$ versus no thapsigargin (D) or versus $5.5 \mathrm{mM}$ glucose $(\mathbf{E}) ;{ }^{\#} P<0.05$ versus thapsigargin (D) Densitometric analyses of the Western blots are an average of 3 lanes per condition. Data in C-E indicate the mean \pm SEM. Differences between groups were assessed by ANOVA with Newman-Keuls multiple comparisons test.
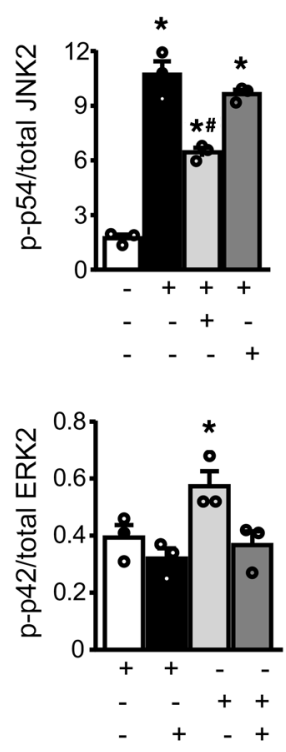
A

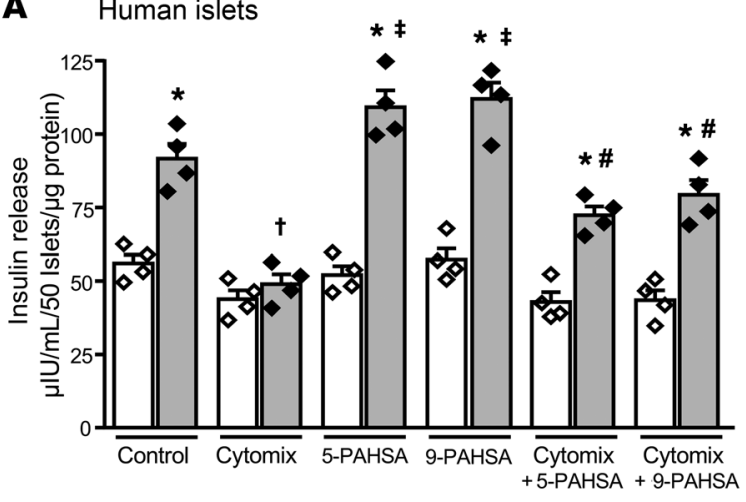

B

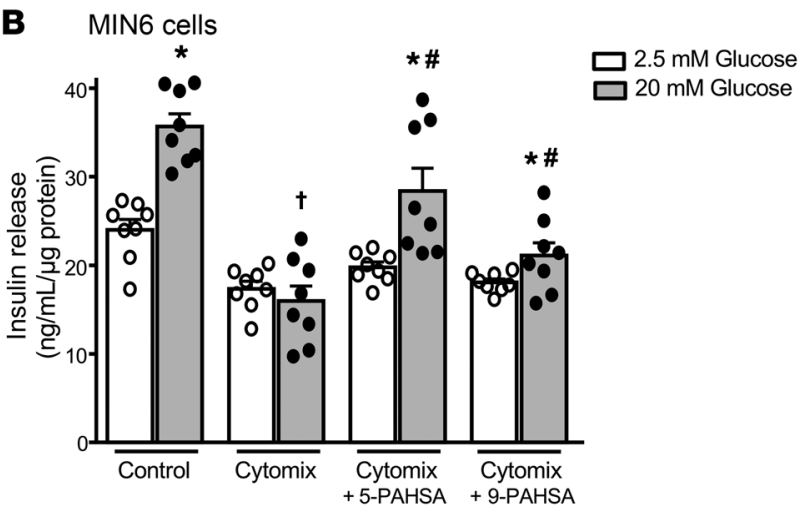

Figure 6. PAHSAs augment GSIS during cytokine-induced $\beta$ cell distress. Human islets (A) and MIN6 cells (B) were treated with cytomix ( $5 \mathrm{ng} / \mathrm{mL}$ TNF- $\alpha$ plus $5 \mathrm{ng} / \mathrm{mL} \mathrm{IL-1 \beta}$ plus $10 \mathrm{ng} / \mathrm{mL}$ IFN- $\gamma)$ in the presence or absence of 5-PAHSA $(20 \mu \mathrm{M})$ or 9-PAHSA $(20 \mu \mathrm{M})$ for 24 hours. At the end of the incubation period, cells were stimulated with low $(2.5 \mathrm{mM})$ and high $(20 \mathrm{mM})$ glucose for 45 minutes in the presence or absence of PAHSAs, and insulin secreted into the buffer was analyzed by ELISA ( $n=4$ wells/condition and 50 islets/well; $n=8$ wells/condition for MIN6 cells). ${ }^{*} P<0.05$ versus respective 2.5 mM glucose; ${ }^{\dagger} P<0.05$ versus control 20 mM glucose; ${ }^{\ddagger} P<0.05$ versus control; ${ }^{\sharp} P<0.05$ versus cytomix 20 mM glucose. Data indicate the mean \pm SEM. Differences between groups were assessed by ANOVA with Tukey's multiple comparisons test.

investigating the role of GPR40 in $\beta$ cell proliferation showed mixed results, we sought to determine whether PAHSA effects on $\beta$ cell proliferation during inflammatory stress are mediated through GLP-1R or GPR40. We tested BrdU incorporation into MIN6 cells subjected to cytokine stress in the presence or absence of 5- and 9-PAHSAs and with or without the GLP-1R antagonist exendin(9-39) or the GPR40 antagonist GW1100. Cytomix treatment reduced MIN6 cell proliferation by 51\% compared with DMSO control, and 5- and 9-PAHSAs increased MIN6 cell proliferation under cytokine stress by $31 \%$ compared with cytomix alone (Figure 3G). Exendin(9-39) alone reduced BrdU incorporation by $15 \%$ compared with the DMSO control, consistent with previous reports which showed that GLP- 1 promotes $\beta$ cell survival and proliferation (31). MIN6 cells treated with cytomix, PAHSAs, and exendin(9-39) together had significantly lower BrdU incorporation into cells compared with treatment with just cytomix and PAHSAs (Figure 3G), but this BrdU incorporation was still higher than that seen with cytomix alone (Figure 3G). However, GW1100 treatment, either alone or in the presence of cytomix and $\mathrm{PAH}-$ SAs, had no effect on BrdU incorporation (Figure 3G). These data suggest that PAHSA effects on $\beta$ cell proliferation under cytokine stress may be mediated in part by GLP-1R, but not GPR 40 .

PAHSA treatment increases islet $\beta$ cell viability and attenuates cytokine-induced $\beta$ cell death by inhibiting ER stress. We next determined whether PAHSAs augment $\beta$ cell viability and attenuate cytokine-induced apoptotic and necrotic $\beta$ cell death in vitro. Treatment of MIN6 cells with either IL-1 $\beta$ or cytomix decreased $\beta$ cell viability as measured by MTT assay (Figure 4A). Both 5-PAHSA and 9-PAHSA increased $\beta$ cell viability during inflammatory stress caused by either IL-1 $\beta$ alone or cytomix at 24,40 , and 48 hours of incubation (Figure $4 \mathrm{~A}$ and Supplemental Figure 4, A and B). The protective effects of PAHSAs with the MTT assay were greatest at 40 hours (Figure $4 \mathrm{~A}$ ). Annexin $\mathrm{V}$ staining reflected apoptotic cell death, and propidium iodide (PI) staining showed necrotic cell death. Cytomix increased the percentage of late apoptotic and necrotic cells by 10- and 15-fold, respectively (Figure 4B). Using this assay, both 5- and 9-PAHSAs maintained $\beta$ cell viability at levels that were comparable to cells not treated with cytomix after 24 hours of incubation. PAHSAs also attenuated cytomix-induced apoptotic and necrotic $\beta$ cell death (Figure $4 \mathrm{~B}$, and see gating strategies in Supplemental Figure 4C). In the MTT assay, the amount of absorbance that indicates cell viability was set to $100 \%$ in DMSO-treated control cells, whereas in the annexin V and PI staining assay, the viable cells were calculated as a percentage of the total number of cells sorted. In parallel, PAHSA-treated NOD mice had fewer apoptotic $\beta$ cells than did vehicle-treated NOD mice (Figure $4, \mathrm{C}$ and D). Therefore, PAHSAs promoted $\beta$ cell survival during cytokine insult by attenuating apoptotic and necrotic cell death.

We next sought to determine whether the beneficial effects of PAHSAs on $\beta$ cell viability during inflammatory stress caused by cytomix treatment are mediated through GLP-1R or GPR40. Cytomix treatment of MIN6 cells induced cell death and reduced cell viability by $62 \%$, and this was partially attenuated by 5 - and 9-PAHSAs (Figure 4E). Exendin(9-39) alone attenuated MIN6 cell viability by $16 \%$ compared with DMSO control. MIN6 cells treated with cytomix, PAHSAs, and exendin(9-39) had significantly lower cell viability than did cells treated with just cytomix and PAHSA (Figure 4E), but their viability was still higher than that seen with cytomix treatment alone (Figure 4E). However, GW1100 treatment either alone or in the presence of cytomix and PAHSAs had no effect on cell viability (Figure 4E). These data suggest that PAHSA effects on $\beta$ cell viability under cytokine stress may be mediated in part by GLP-1R but not GPR40.

Cytokine-induced pancreatic $\beta$ cell death is mediated via ER stress (32). Therefore, we investigated whether the protective effects of PAHSAs are mediated by attenuation of ER stress. PAHSA-treated NOD mice showed lower staining for ER stress markers including XBP-1, an unfolded protein response-regulated transcription factor, and CCAAT/enhancer-binding protein homologous protein (CHOP) in insulin-containing $\beta$ cells compared with vehicle treatment (Figure 5, A and B, and Supplemental Figure 5A). In addition, thapsigargin induced ER stress and poly (ADP-ribose) polymerase (PARP) cleavage in isolated human 
islets. Treatment of human islets with either 5- or 9-PAHSA reduced thapsigargin-induced PARP cleavage, as demonstrated by a lower ratio of cleaved PARP to uncleaved PARP compared with thapsigargin treatment alone (Figure 5C and Supplemental Figure 5, B and C). We observed similar beneficial effects of PAHSAs on PARP cleavage in MIN6 cells (data not shown). Cytokine-induced ER stress triggered apoptotic $\beta$ cell death by activating MAPKs such as JNK1/2 and ERK1/2. In MIN6 cells, 5-PAHSA attenuated thapsigargin-induced JNK1 and JNK2 phosphorylation, and 9-PAHSA attenuated thapsigargin-induced JNK1 phosphorylation (Figure 5D). In addition, high glucose levels induced phosphorylation of ERK2 (and not ERK1) in MIN6 cells, and this was attenuated by PAHSAs (Figure $5 \mathrm{E}$ ).

Another major mechanism by which cytokines induce pancreatic $\beta$ cell death is through activation of inducible NOS with subsequent generation of nitric oxide (NO) (33). Therefore, we investigated whether the protective effects of PAHSAs on cytokine-induced $\beta$ cell survival are mediated by attenuation of NO release. We found that cytomix increased NO release in both isolated human islets and MIN6 cells and that treatment with 5- and 9-PAHSAs did not reduce NO release (Supplemental Figure 5D). These data suggest that the beneficial effects of PAHSAs on attenuation of cytokine-induced $\beta$ cell death are independent of the NO pathway. Taken together, these data indicate that PAHSAs augment $\beta$ cell viability and protect against cytokine-induced $\beta$ cell death, and this may be mediated by their effects to attenuate ER stress and reduce JNK and ERK activation.

PAHSAs augment GSIS during cytokine-induced $\beta$ cell distress. Cytokines attenuate insulin secretion from pancreatic $\beta$ cells in addition to causing $\beta$ cell destruction $(34,35)$. Here, we examined whether PAHSAs can maintain GSIS during cytokine-mediated $\beta$ cell distress. In human islets and MIN6 cells, treatment with 5- or 9-PAHSA alone potentiated GSIS only at high- and not at low-glucose concentrations (Figure 6, A and B), as reported previously $(25,30)$. Cytomix treatment decreased insulin secretion at a high $(20 \mathrm{mM})$ glucose concentration in human islets and MIN6 cells (Figure 6, A and B). 5- or 9-PAHSA partially blocked the effect of cytomix to reduce GSIS at a high glucose concentration in both human islets (Figure 6A) and MIN6 cells (Figure 6B). Together, these data suggest that PAHSAs potentiate GSIS, attenuate $\beta$ cell death, and augment $\beta$ cell proliferation during cytokine insult.

\section{Discussion}

T1D develops as a result of autoimmune-mediated $\beta$ cell destruction resulting in insulin deficiency. To our knowledge, despite clinical trials involving many different immune-modulatory agents, no intervention has yet been found that has sustained effects and can be utilized safely over many years without adverse effects. Here, we demonstrate that the endogenous mammalian lipids PAHSAs reduce the incidence and delay the onset of T1D in NOD mice and improve their survival. PAHSAs are effective in both early intervention and late intervention, when insulitis is established (Figure $1, C$ and D), which is more likely to resemble the stage when people at risk for T1D are islet antibody positive but do not yet have overt diabetes. In our study, PAHSAs appeared to exert both direct protective effects on $\beta$ cells and antiinflammatory effects on immune cells. Furthermore, prolonged PAHSA treatment (for at least 6.5 months) is safe, since data on multiple strains of mice using different diets and routes of administration showed no organ toxicity, as assessed by histology and functional assays (Supplemental Figure $1 G$, our unpublished data, and ref. 36). As another indication of the safety of PAHSAs, mice that maintain markedly elevated PAHSA levels throughout their lifetimes due to a genetic manipulation are healthy, reproduce normally, show no adverse effects, and have a normal lifespan $(25,37)$.

Both T cells and B cells play a role in T1D pathogenesis (4, $5)$. $\mathrm{T}$ cell-mediated immunity is primarily responsible for inflammation-associated $\beta$ cell death (38). CD4 ${ }^{+} \mathrm{T}$ cells are capable of differentiating into several subsets. For example, IL-12 triggers the differentiation of Th1 cells and inhibits the differentiation of Th2 cells (39). Cytokines such as IFN- $\gamma$ and IL-2 derived from Th1 cells stimulate $\mathrm{CD} 8^{+} \mathrm{T}$ cells and macrophages to promote a proinflammatory response against islet $\beta$ cells (40). In the current study, we demonstrated that chronic PAHSA treatment prevented an increase in leukocytes $\left(\mathrm{CD} 45^{+}\right.$cells) in pancreatic infiltrates in vehicle-treated NOD mice from 11 to 15 weeks of age (Figure 2C). In addition, PAHSA treatment attenuated $\mathrm{CD}^{+}$and $\mathrm{CD}^{+} \mathrm{T}$ cell activation (Figure 2D) and reduced the fractional representation of B cells (Supplemental Figure 2, A and B). This is in accordance with studies demonstrating that a reduction in $\mathrm{B}$ cell numbers and function attenuates $\mathrm{CD} 4^{+} \mathrm{T}$ cell expansion and T1D development (41).

In addition to $\mathrm{CD} 4^{+}$and $\mathrm{CD} 8^{+} \mathrm{T}$ cell changes, patients with T1D have decreased numbers of Tregs and an elevated percentage of Th17 cells. Tregs are essential suppressors of unwanted autoimmune responses and are thought to modulate $\mathrm{T}$ cell activation and promote tolerance by suppressing adaptive immunity (42). Th17 cells are an IL-17-producing subset of Th cells that are distinct from Th1 and Th2 lineages. Specific anti-IL-17 antibodies and stem cell-based therapies have increased Treg populations in NOD mice, which suppresses immune attack (43). In this context, PAHSA treatment in NOD mice increased Foxp3 protein expression in pancreatic infiltrates (Figure $2 \mathrm{G}$ ). Taken together, PAHSAmediated changes in $\mathrm{T}$ and $\mathrm{B}$ cell populations are likely to play a major role in the beneficial effects of PAHSAs in decreasing T1D incidence in NOD mice.

Islet $\beta$ cell proliferation in adult humans and rodents is minimal and controlled by age-dependent intrinsic and extrinsic factors (44). For example, in younger mice, exendin-4 and partial pancreatectomy induce $\beta$ cell proliferation, but this is markedly attenuated in older mice (45). Furthermore, there are clear species differences in $\beta$ cell proliferation, since murine $\beta$ cells show a higher proliferative response (10\%-15\%) compared with human $\beta$ cells following physiological alterations and during embryonic life. Many growth factors and mitogens have proliferative effects in rodent models, whereas, in human islets their effects are minimal ( $0.2 \%$ of $\beta$ cells $/ 24$ hours in vitro) (46). In contrast, $\beta$ cell replication and neogenesis are important during embryonic development, for postnatal $\beta$ cell growth, and in response to injuries (47, 48). Neogenesis can be achieved via differentiation of progenitors within the ductal epithelium (49) or through transdifferentiation of acinar cells (50) or $\alpha$ cells (51) into $\beta$ cells. Molecules that increase $\beta$ cell numbers are actively being sought to prevent and treat T1D in humans. In this context, PAHSA-treated NOD mice displayed 
an increase in $\beta$ cell numbers compared with vehicle-treated NOD mice (Figure 3C). This resulted from increased $\beta$ cell proliferation along with reduced immune cell infiltration demonstrated by more insulin-positive cells which are also positive for Ki67 in nondiabetic PAHSA-treated mice compared with nondiabetic vehicle-treated mice (Figure 3D). The proliferative effects in NOD mice did not depend on hyperglycemia, since all vehicle- and PAHSA-treated mice for these studies were nondiabetic and had glycemia levels below $150 \mathrm{mg} / \mathrm{dL}$ following ad libitum feeding. This increased $\beta$ cell proliferation was also demonstrated by tracer dilution studies and BrdU incorporation into MIN6 cells (Figure 3, E and F). This proliferation appeared to be mediated in part by GLP-1R and not by GPR40 (Figure 3G). To determine how generalizable the proliferative effects are, we evaluated $\beta$ cell proliferation in nondiabetic chow-fed C57Bl/6J mice that received chronic PAHSA treatment and found no effect on $\beta$ cell proliferation compared with vehicle treatment (data not shown). The differences in the data for nondiabetic NOD mice and C57Bl/6J mice could be due to the differences in the mouse strains, the presence of insulitis in the nondiabetic NOD mice, and the age of the mice.

During T1D disease progression, autoantigens released as a result of $\beta$ cell death trigger the proliferation and activation of immune cells and a subsequent release of proinflammatory cytokines and excessive generation of free radicals (34). These cytokines and free radicals induce ER stress (32) in healthy $\beta$ cells and cause apoptotic cell death via multiple pathways including activation of MAPKs such as ERK and JNK $(32,52,53)$. Here, we show that PAHSA treatment not only attenuated immune responses but also acted directly on islet $\beta$ cells to block cytokine-induced cell death and increase cell viability (Figure 4, A-E and Supplemental Figure 4, A and B). The mechanisms for these effects likely include a PAHSA-mediated reduction in ER stress (Figure 5, A-C) and ERK and JNK activation (Figure 5, D and E), which appeared to be mediated in part by GLP-1R and not by GPR40 (Figure 4E). In addition to the effects on cell survival, PAHSA treatment improved GSIS in human islets and cultured $\beta$ cells exposed to proinflammatory cytokines (Figure 6, A and B).

Other lipid classes including sphingosine-1-phosphate, omega-3 fatty acids, and resolvins have also been shown to reduce autoimmunity and improve $\beta$ cell function in NOD mice $(16,18$, 23). However, the results from studies in humans are mixed. For example, supplementation with cod liver oil, which is rich in omega-3 fatty acids, during the first year of life was associated with a lower risk of childhood-onset T1D (54). A recent TrialNet Nutritional Intervention to Prevent (NIP) Type 1 Diabetes Study in infants at high genetic risk for T1D showed that docosahexaenoic acid (DHA) supplementation resulted in a transient lowering of high-sensitivity $\mathrm{C}$-reactive protein and inflammatory cytokines at 12 months of age in DHA-treated infants compared with infants who did not receive DHA (55). However, inflammatory cytokine production by leukocytes from these subjects was not consistently reduced at 36 months (55). In another longitudinal observational study, the Diabetes Autoimmunity Study in the Young (DAISY), initial data suggested that an increased intake of omega-3 fatty acids resulted in higher erythrocyte membrane omega- 3 fatty acid levels, which were associated with a decreased risk of developing anti-islet autoantibodies (19). However, the follow-up stud- ies did not show that omega-3 fatty acid treatment decreased the risk of T1D (56). Therefore, there is still a major need for agents that attenuate autoimmunity, prevent and treat $\beta$ cell loss in T1D, promote $\beta$ cell function, and are safe for life-long therapy. Since PAHSAs attenuate autoimmunity and also have direct effects on $\beta$ cell survival and function, they may be effective in preventing and treating $\mathrm{T} 1 \mathrm{D}$ in humans.

Many of the effects of PAHSAs demonstrated here in NOD mice are similar to the effects of omega-3 fatty acids. These include a reduction of $\mathrm{T}$ cell-mediated autoimmunity and lymphocyte infiltration into islets, promotion of $\beta$ cell proliferation, and restoration of islet function. Both PAHSAs and omega-3 fatty acids are signaling lipids that activate the GPCRs GPR120 and GPR40. PAHSAs directly bind to and activate GPR40, which is involved in the beneficial effects of PAHSAs on GSIS in isolated human islets (30). To our knowledge, it has not been shown whether omega-3 fatty acids directly bind to GPCRs. Furthermore, in isolated human islets and MIN6 cells, PAHSAs have direct beneficial effects by promoting $\beta$ cell survival and function. This appears to be mediated, at least in part, by attenuation of ER stress and reduction of the activation of MAPKs. Although omega-3 fatty acids also reduce MAPK activation, there are no data, to our knowledge, that show direct effects of omega-3 fatty acids on the suppression of ER stress in islets. Fish oil supplementation attenuates ER stress in white adipose tissue (WAT) in high-fat diet-fed (HFD-fed) obese mice, but this has not been shown to be a direct effect (57).

Given that FAHFAs are synthesized $(25,26)$ and degraded (58) in mammalian tissues, it is possible that their levels could be increased by targeting biosynthetic or degradative enzymes. The fact that some of the PAHSA hydrolytic enzymes have specific tissue distributions $(58,59)$ may allow targeted increases in PAHSA levels to avoid more systemic immunosuppression. In this context, we recently identified carboxyl ester lipase (CEL) as a FAHFA hydrolase that is highly expressed in pancreatic acinar tissue and hydrolyzes FAHFAs at a much higher rate compared with previously known substrates such as triacylglycerols, diacylglycerols, and cholesteryl esters (58). CEL appears to be a major PAHSA hydrolase in the pancreas, since PAHSA hydrolysis was low in pancreatic membranes from CEL-KO mice compared with membranes from WT littermates (58). A gain-of-function mutation in CEL causes maturity-onset diabetes of the young type-8, which is characterized by pancreatic islet and acinar dysfunction (60). This mutation results in increased FAHFA hydrolysis (60), which may reduce FAHFA levels. Thus, not only do FAHFAs have the potential to be used as therapeutic agents to treat T1D, but it may be possible to regulate their levels specifically in pancreas, which could be safer than other immune-mediated approaches that can cause systemic immune suppression.

A recent report challenged the finding that PAHSAs have beneficial metabolic effects in HFD-fed mice (61). Many important methodological issues contributed to the different results, and several of these were discussed by Pflimlin et al. (61). In our response (36) and in a separate response by Ondrej Kuda (62), the experimental problems with these studies were extensively discussed.

Regarding the inability of the study by Pflimlin et al. to detect augmentation of GSIS by PAHSAs in pancreatic islets, a recent study corroborated our results using a completely different 
methodology, i.e., microfluidics (63). That study showed that in human islets from both healthy and type 2 diabetic donors and in murine islets, 5-PAHSA increased the total amount of GSIS and also improved the dynamic insulin release profiles, as indicated by more pronounced insulin oscillations. The absence of PAHSA effects on GSIS in the Pflimlin et al. report may result from substantial differences in the study protocols compared with those of previous studies $(25,30,36)$. For studies of GLP-1 secretion in refs. 25 and 31 compared to those in ref. 61, different cell lines were used that have a different constellation of fatty acid receptors.

In conclusion, we found that PAHSAs attenuate autoimmune responses involving subsets of both T and B cells and promote $\beta$ cell proliferation in vivo. Direct protective effects independent of the immune system were also evident, since PAHSAs attenuated cytokine-induced apoptotic and necrotic $\beta$ cell death and increased $\beta$ cell viability and proliferation in MIN6 cells. The mechanism appears to involve a reduction of ER stress, since PAHSAs lowered ER stress in islets of NOD mice. This appeared to be a direct effect, as PAHSAs suppressed thapsigargin-induced ER stress in human islets and MIN6 cells. PAHSAs also prevented impairment in GSIS and improved glucose tolerance in NOD mice, both of which could have resulted from decreased $\beta$ cell apoptosis and increased $\beta$ cell numbers.

Limitations of studies in NOD mice. A number of agents can prevent or even reverse T1D in NOD mice. However, these successes have failed to translate to human clinical trials (24) for many reasons including but not limited to (a) species differences in immune cells and immune responses and in pancreatic $\beta$ cells in humans and mice $(24,64)$, (b) genetic heterogeneity that affects the immune system $(24,65)$, (c) differences in the gut microbiome that may play a role in susceptibility to T1D (66), (d) environmental factors (66), and (e) the dosage and timing of interventions (24). A comprehensive review by Reed and Herold discussed preclinical studies in NOD mice and the results of clinical trials, focusing on the reasons for the differences between the NOD mouse model and humans with T1D (24).

Thus, with these caveats, PAHSAs may be beneficial in reducing the risk of developing T1D in islet antibody-positive individuals and may promote $\beta$ cell survival and proliferation and enhance insulin secretion in individuals newly diagnosed with T1D. Since PAHSAs also delay the onset and reduce the severity of colitis (28), they may also be effective in treating other autoimmune diseases.

\section{Methods}

Animals. Female NOD chow-fed (Purina Lab Diet, 5008) mice (The Jackson Laboratory) were randomized to treatment groups on the basis of body weight at 4 weeks of age and received $15 \mathrm{mg} / \mathrm{kg} 5$ - and 9-PAHSA each or an equal volume of vehicle (50\% PEG400 plus $49.5 \%$ saline plus $0.5 \%$ Tween- 80 ) by oral gavage. All mice were housed in ventilated cages with ad libitum access to food and water. Mice were maintained on a 14 -hour light/10-hour dark schedule at $72^{\circ} \mathrm{F}$ to $74^{\circ} \mathrm{F}$. body weight, food intake, and glycemia were measured weekly. Onset of T1D in female NOD mice was defined by blood glucose levels above $250 \mathrm{mg} / \mathrm{dL}$ for 2 consecutive weeks following ad libitum feeding. Mice were bled in the ad libitum fed state from the tail vein, and blood was transferred into tubes and serum insulin levels measured by ELISA. At the end of the study, the mice were sacrificed by decapitation for serum collection, and tissues were harvested and then snap-frozen in liquid nitrogen and stored at $-80^{\circ} \mathrm{C}$ until further use or placed in $10 \%$ formalin for histological analysis.

5- and 9-PAHSAs. PAHSAs were synthesized in-house. We studied 5- and 9-PAHSAs for the following reasons: (a) 9-PAHSA was the most abundant form in adipose tissue in WT mice and in subcutaneous WAT of humans (25); (b) 5-PAHSA was the most consistently downregulated in all adipose depots and in the serum of insulin-resistant mice and in WAT and serum of insulin-resistant humans (25); (c) in vitro, 5- or 9-PAHSAs directly enhance GLP-1 secretion from enteroendocrine cells and GSIS from human islets (25); (d) acute oral treatment with 5- or 9-PAHSA isomers improves glucose tolerance in aged chow-fed and HFD-fed mice and augments insulin and GLP-1 secretion in vivo in aged chow-fed mice (25); and (e) 5- and 9-PAHSAs have antiinflammatory effects including a decrease in adipose tissue inflammation in HFD-fed mice, a delay in the onset and reduction of the severity of colitis in a mouse model, and attenuation of LPS-induced dendritic cell activation and cytokine production $(25,28,30)$.

Materials and chemical reagents. All chemical reagents were from MilliporeSigma unless otherwise stated. Insulin, glucagon, Ki67, PARP, JNK1/2, and ERK1/2 antibodies were purchased from Cell Signaling Technology. Cytokines (IL- $1 \beta, \mathrm{TNF}-\alpha$, and IFN- $\gamma$ ) were purchased from R\&D Systems. Exendin(9-39) was purchased from BACHEM. GW1100 was purchased from Cayman Chemical. Antibodies for flow cytometry were purchased from BioLegend and eBioscience. ELISA kits were obtained from Crystal Chem (mouse insulin) and Alpco Diagnostics (human insulin). Both 5- and 9-PAHSAs were synthesized on the basis of established methods (67). MIN6 cells were obtained from the American Type Culture Collection (ATCC).

Human islet source and demographic details. Human islets from nondiabetic donors were obtained from the Boston Area Diabetes and Endocrinology Research Center (BADERC) Core Facility (Massachusetts General Hospital) and Prodo Laboratories Inc. The studies were performed using islets from 4 different human donors. Table 1 includes details on the human islet sources and demographics.

GSIS in human islets. GSIS was assessed as described previously (68). Briefly, human islets or MIN6 cells were treated with either vehicle or cytomix (TNF- $\alpha$ plus IL-1 $\beta$ plus IFN- $\gamma ; 5 \mathrm{ng} / \mathrm{mL}$ plus $5 \mathrm{ng}$ / $\mathrm{mL}$ plus $10 \mathrm{ng} / \mathrm{mL}$ ) in the continuous presence or absence of 5 - and 9-PAHSA ( $20 \mu \mathrm{M}$ each) for 24 hours. At the end of treatment, islets or MIN6 cells were incubated in Krebs-Ringer bicarbonate buffer with $0.5 \%$ BSA (pH 7.4) for 2 hours and stimulated with $2.5 \mathrm{mM}$ (low) and $20 \mathrm{mM}$ (high) glucose for 45 minutes. Media were collected and insulin quantitated by ELISA.

GSIS and OGTT in NOD mice in vivo. For GSIS studies, mice were bled from the tail vein at $t_{0}$ (baseline) and 8 minutes after glucose gavage, blood was transferred into tubes, and serum insulin levels were measured by ELISA. An OGTT ( $1 \mathrm{~g} / \mathrm{kg}$ glucose by gavage) was performed as described previously (25) following 5 hours of food removal. Glycemia was monitored for 1 hour.

PAHSA extraction and measurements in serum and tissues. Lipid extraction was performed as described previously (69). Serum (100 $\mu \mathrm{L}$ ) and tissues (60-100 mg) were Dounce-homogenized on ice in a mixture of $1.5 \mathrm{~mL} \mathrm{MeOH}, 1.5 \mathrm{~mL}$ chloroform, and $3 \mathrm{~mL}$ citric acid buffer. The final mixture was centrifuged, and the organic phase containing lipids was dried under $\mathrm{N} 2$ and stored at $-80^{\circ} \mathrm{C}$ prior to solid-phase extraction (69). 


\section{Table 1. Human islet source and demographic details}

$\begin{array}{lcccc}\text { Human donor ID } & \text { Donor 1 } & \text { Donor 2 } & \text { Donor 3 } & \text { Donor 4 } \\ \text { Source } & \text { MGH } & \text { Prodo Labs } & \text { Prodo Labs } & \text { Prodo Labs } \\ \text { Age (yr) } & 45 & 40 & 61 & 66 \\ \text { Race/ethnicity } & & \text { Hispanic } & \text { Hispanic } & \text { White } \\ \text { Sex } & \text { Male } & \text { Male } & \text { Male } & \text { Male } \\ \text { Height (in.) } & 71 & 69 & 66 & 67 \\ \text { Weight (Ib.) } & 214 & 172 & 179 & 174 \\ \text { BMI } & 29.6 & 25 & 28.8 & 27 \\ \text { History of diabetes } & \text { No } & \text { No } & \text { No } & \text { No } \\ \text { HbA1C (\%) } & 5.1 & 5.3 & 5.1 & 4.7 \\ \text { Cause of death } & \text { Choking } & \text { Head trauma } & \text { Stroke } & \text { Stroke } \\ \text { Islet purity } & 90 \% & 85 \% & 90 \% & 90 \%-95 \% \\ \text { Islet viability } & 95 \% & 95 \% & 95 \% & 95 \%\end{array}$

Prodo Labs, Prodo Laboratories Inc.; MGH, BADERC Core Facility at Massachusetts General Hospital (Boston, Massachusetts, USA); HbA1C, hemoglobin A1C.

Cell viability MTT assay. MIN6 cells were treated with IL-1及 (10 $\mathrm{ng} / \mathrm{mL}$ ) and/or cytomix (TNF- $\alpha$ plus IL-1 $\beta$ plus IFN- $\gamma ; 10 \mathrm{ng} / \mathrm{mL}$ each) in the presence or absence of 5-PAHSA $(5 \mu \mathrm{M})$ and/or 9-PAHSA $(5 \mu \mathrm{M})$, exendin(9-39) (10 nM) or GW1100 (10 $\mu \mathrm{M})$ for 24, 40, and 48 hours. At the end of the treatment, MTT reagent $(10 \mu \mathrm{L} /$ well $)$ was added, and cells were incubated for 2 hours. The formazan product formed was solubilized by adding MTT detergent, and absorbance was measured at $570 \mathrm{~nm}$. The amount of absorbance is directly proportional to the number of viable cells. This assay measures the metabolic activity (mainly succinate dehydrogenase) of the viable cells and quiescent cells (early apoptotic). This activity is very low in late apoptotic cells and absent in necrotic cells.

NO measurements. Human islets or MIN6 cells were treated with either vehicle or cytomix (TNF- $\alpha$ plus IL- $1 \beta$ plus IFN- $\gamma ; 5 \mathrm{ng} / \mathrm{mL}$ plus $5 \mathrm{ng} / \mathrm{mL}$ plus $10 \mathrm{ng} / \mathrm{mL}$ ) in the continuous presence or absence of 5- and 9-PAHSA ( $20 \mu \mathrm{M}$ each) for 24 hours. Media were collected, and NO release was quantitated according to the manufacturer's protocol using a modified Griess Reagent Kit (Invitrogen, Thermo Fisher Scientific).

Insulitis score. NOD mice were treated with vehicle and 5- and 9-PAHSAs orally from 4 weeks to 10 weeks of age. Pancreata were excised for histological analysis after 6 weeks of treatment, and insulitis was visualized by H\&E staining of paraffin-embedded sections. Three H\&E-stained step sections (150- $\mu \mathrm{m}$ apart) per tissue were evaluated, with individual islets scored in a blinded fashion according to the following scheme: no insulitis (0), peri-insulitis (1, perivascular/ periductular infiltrates with leukocytes contacting islet perimeters), or intra-insulitis (2, leukocytic penetration present within the $\beta$ cell mass). Peri-insulitis or intra-insulitis was defined by the presence of more than 10 leukocytes per islet. A total of 50 to 100 islets per mouse were scored for insulitis.

Flow cytometry. For immune cells, all staining began by incubation with a mAb against the following antigens: CD45 (30-F11), CD4 (RM4-5), CD8 (53-6.7), CD19 (6D5), CD62L, IFN- $\gamma$, IL-17A (TC1118H10.1), PD-1 ${ }^{+}$, CD86 (all from BioLegend), and Foxp3 (eBioscience). Pancreatic lymph nodes were removed from pancreata prior to digestion. For whole pancreata digestion, mice were perfused with 10 $\mathrm{ml}$ PBS via the left ventricle prior to organ harvesting. Pancreata were dissected, minced, and subsequently incubated in $25 \mathrm{ml}$ DMEM with 2\%FBS plus collagenase IV $1 \mathrm{mg} / \mathrm{ml}$ (Gibco, Thermo Fisher Scientific) and DNAseI $10 \mathrm{U} / \mathrm{ml}$ (MilliporeSigma) at $37^{\circ} \mathrm{C}$ for 20 minutes in a shaking incubator. Cells were washed and filtered through a $70-\mu \mathrm{m}$ cell strainer prior to staining. Cells were stained on ice for 30 minutes at $4^{\circ} \mathrm{C}$ in FACS buffer (DMEM with 2\% FBS and Fc block) (29). Foxp3 (eBioscience) staining was performed according to the manufacturer's protocol. To assess cytokine production, pancreatic single-cell suspensions were restimulated with PMA and ionomycin in the presence of GolgiPlug for 3.5 hours at $37^{\circ} \mathrm{C}$ prior to intracellular staining. For analysis, stained cells were run on a BD LSR II flow cytometer and analyzed using FlowJo Software (Tree Star).

Annexin V and PI staining assay. MIN6 cells were grown to $60 \%$ to $70 \%$ confluence and treated with cytomix (TNF- $\alpha$ plus IL-1 $\beta$ plus IFN- $\gamma ; 5 \mathrm{ng} / \mathrm{mL}$ plus $5 \mathrm{ng} / \mathrm{mL}$ plus $10 \mathrm{ng} / \mathrm{mL}$ ) in the presence or absence of 5- and 9-PAHSA ( $20 \mu \mathrm{M}$ each) for 24 hours. At the end of treatment, cells were stained with annexin V and PI for 15 minutes, and flow cytometry was performed to evaluate the number of viable, apoptotic, and necrotic $\beta$ cells.

Determination of islet $\beta$ cell and $\alpha$ cell area. Pancreata from NOD mice treated chronically with vehicle or 5- and 9-PAHSA by daily oral gavage for 7 weeks were collected and fixed in 10\% formalin. In order not to analyze the same islets in more than 1 section, we cut sections that were separated by $150 \mu \mathrm{m}$. Using immunofluorescence staining, islet $\beta$ cell and $\alpha$ cell areas were determined by quantifying the pixels in 11 to 26 islets from triplicate sections of the pancreas from each animal. Complete sections of pancreas were stained for insulin, glucagon, and DAPI and scanned using the Zeiss LSM510 upright confocal microscope. The percentage of $\beta$ and $\alpha$ cell area per islet was determined by measuring the pixels in the insulin and glucagon areas, respectively, divided by the total number of pixels (ROI, drawn around the islet) in the entire islet using Image J software (NIH). Only those islets containing 3000 pixels or more were used for final individual islet quantification. The following antibodies were used to label $\alpha$ cell and $\beta$ cell areas, respectively: rabbit antiglucagon (1:400; Cell Signaling Technology, CST8233S) and guinea pig anti-insulin (1:200; Abcam, ab7842).

Quantification of ER stress markers. The same staining protocol used for the determination of $\beta$ and $\alpha$ cell area was applied for quantification of the ER stress markers XBP-1 (1:200; Abcam, ab37152) and DDIT3 (also known as CHOP) (1:200; Abcam, ab11419) immunofluorescence. Staining was quantified in approximately 15 islets per sample. Using Image J software, each islet image was split into different channels for each specific staining to obtain 1 image per channel, and the ROI was drawn around the stained area. Then, the ratio of the sum of stained pixel intensities versus the islet area was calculated using ImageJ software.

Quantification of individual $\beta$ cell size, volume, and mean number of $\beta$ cells per islet. The mean individual $\beta$ cell cross-sectional area was determined as the insulin-positive area of each islet divided by the number of nuclei within the insulin-positive area. Five islets per animal (5 animals per condition) were selected at random. The $\beta$ cell volume per islet was calculated from the mean individual $\beta$ cell cross-sectional area. The mean number of $\beta$ cells per islet was calculated by dividing the total $\beta$ cell area per islet by the mean cross-sectional area per individual $\beta$ cell. 
Determination of apoptosis in vivo. Female NOD mice were treated with either PAHSA or vehicle for 15 weeks starting at 4 weeks of age. TUNEL staining was performed on pancreata sections from $\mathrm{PAH}-$ SA- and vehicle-treated NOD mice to identify apoptosis, following the manufacturer's instructions (MilliporeSigma, ApoTag Red In situ Apoptosis Detection Kit), in addition to insulin staining (1:200; Abcam, ab7842) to identify insulin-positive $\beta$ cells. Only insulin-positive $\beta$ cells with TUNEL-positive nuclei were included for quantification.

Determination of proliferation in vivo. Proliferation was assessed in islets and liver sections by immunofluorescence staining for Ki67 (1:200; Thermo Fisher Scientific, RM-9106-R7). Using ImageJ software $(\mathrm{NIH})$, each islet was scored for the number of insulin-positive cells, Ki67 ${ }^{+}$cells, and cells with double-positive staining for insulin and Ki67. The percentage of proliferating $\beta$ cells was calculated as the total number of cells double-positive for insulin and Ki67 divided by the total number of insulin-positive cells in that islet. The percentage of Ki $67^{+}$cells in the liver was calculated as the percentage of cells double-positive for Ki67 and DAPI, normalized to the total number of DAPI-stained nuclei per field.

Cell tracer assay. MIN6 cells at 0\% confluence were stained with CellTrace Violet (Thermo Fisher Scientific) for 15 minutes and treated along with IL-1 $\beta(10 \mathrm{ng} / \mathrm{mL})$ in the presence or absence of 5- or 9-PAHSA $(5 \mu \mathrm{M}$ or $20 \mu \mathrm{M})$ for 48 hours. At the end of the treatment period, cells were harvested, acquired in a BD LSR II flow cytometer, and analyzed with FlowJo software to determine the $\beta$ cell proliferation index. Approximately 5000 cells were sorted for each condition.

BrdU proliferation assay. MIN6 cells were treated with cytomix (TNF- $\alpha$ plus IL- $1 \beta$ plus IFN- $\gamma ; 10 \mathrm{ng} / \mathrm{mL}$ each) in the continuous presence or absence of 5- and/or 9-PAHSA (20 $\mu \mathrm{M})$, exendin(9-39) $(10 \mathrm{nM})$ or GW1100 $(10 \mu \mathrm{M})$ for 24 and 48 hours. At the end of the treatment, a BrdU proliferation assay (EMD Millipore, catalog QIA58200TEST) was performed according to the manufacturer's protocol. The amount of absorbance was directly proportional to the number of proliferative $\beta$ cells.

Western blot analyses. Human islets were treated with thapsigargin $(2 \mu \mathrm{mol} / \mathrm{L})$ for 6 hours in the continuous presence or absence of 5- or 9-PAHSA ( $20 \mu \mathrm{M}$ each). MIN6 cells were treated with thapsigargin $(0.5 \mu \mathrm{mol} / \mathrm{L})$ for 6 hours or high glucose $(25 \mathrm{mM})$ for 24 hours in the presence or absence of 5- and/or 9-PAHSA (20 $\mu \mathrm{M}$ each). At the end of the treatment, cells were collected, and Western blotting was performed to determine for PARP cleavage as well as levels of phosphorylated JNK1/2 (p-JNK1/2), total JNK1/2, p-ERK1/2, and total ERK1/2. ACTB and GAPDH were used as housekeeping genes.

Analytical procedures. Serum ALT and creatinine were measured using colorimetric enzyme assay kits (MilliporeSigma). Liver triglycerides were extracted and measured as previously described (70).

Statistics. All statistical analyses were performed using GraphPad Prism (GraphPad Software), and differences were considered significant when $P$ values were less than 0.05. All values represent the mean \pm SEM. Differences between groups were assessed with a 2-tailed Student's $t$ test, a repeated-measures ANOVA, or ANOVA with Bonferroni's, Tukey's, or Newman Keuls multiple comparisons test. A log-rank (Mantel-cox) test was used to assess the cumulative diabetes incidence. This was also confirmed using the log-rank test at http:// www.evanmiller.org/ab-testing/survival-curves.html.

Study approval. All animal care and use procedures were conducted in strict accordance with and approved by the IACUC of Beth Israel Deaconess Medical Center.

\section{Author contributions}

IS conceived of, designed, performed, and interpreted experiments and prepared figures. JFM and PMMV designed, performed, and interpreted the immunology experiments and prepared figures. $\mathrm{AV}$ assisted with in vivo and in vitro studies. MFRDC performed and interpreted islet histology experiments and prepared the corresponding figures. ATN, DS, and AS designed and performed chemical synthesis of the lipids. DM conceived of, designed, supervised and interpreted the immunology experiments. BBK conceived of the overall experimental plan and designed, supervised, and interpreted experiments. BBK and IS wrote the manuscript. DM, PMMV, and AV edited the manuscript.

\section{Acknowledgments}

We thank Ji Lei, director of the BADERC (P30 DK57521) Pancreatic Islet Core, for providing human islets. We thank Susan Bonner-Weir, director of the Joslin DRC Advanced Microscopy Core (NIH P3O DK036836), for her expertise and conversations related to islet biology analyses. Imaging was performed at the Neuro Imaging Facility of Harvard Medical School (NINDS P30 Core Center Grant NS072030) for $\beta$ and $\alpha$ cell area quantification. We thank Kerry Wellenstein and Pratik Aryal for performing Western blot analyses and Anna Santoro for assistance with in vivo studies (all from Beth Israel Deaconess Medical Center). This work was supported by grants from the NIH (R01 DK43051 and P30 DK57521, to BBK; R01 DK106210, to BBK and AS; and K01 DK118041, to IS); a Deutsche Forschungsgemeinschaft (DFG) Fellowship (MFRDC); and by grants from the JPB Foundation (to BBK and DM).

Address correspondence to: Barbara B. Kahn, Division of Endocrinology, Diabetes and Metabolism, Department of Medicine, Beth Israel Deaconess Medical Center and Harvard Medical School, Center for Life Sciences, Room 747, 330 Brookline Avenue, Boston, Massachusetts 02215, USA. Phone: 617.735.3324; Email: bkahn@bidmc.harvard.edu.

PMMV's present address is: Department of Genetics, Evolution, Microbiology and Immunology, Institute of Biology, University of Campinas, Campinas-SP 13083-970, Brazil.
1. Rabinovitch A. Immunoregulatory and cytokine imbalances in the pathogenesis of IDDM. Therapeutic intervention by immunostimulation? Diabetes. 1994;43(5):613-621.

2. Maahs DM, West NA, Lawrence JM, Mayer-Davis EJ. Epidemiology of type 1 diabetes. Endocrinol
Metab Clin North Am. 2010;39(3):481-497. 3. Ehehalt S, Dietz K, Willasch AM, Neu A, DIARY-Group Baden-Wuerttemberg. Prediction model for the incidence and prevalence of type 1 diabetes in childhood and adolescence: evidence for a cohort-dependent increase within the next two decades in Germany. Pediatr Diabetes. 2012;13(1):15-20.

4. Herold KC, et al. Prevention of autoimmune diabetes with nonactivating anti-CD3 monoclonal antibody. Diabetes. 1992;41(3):385-391.

5. Herold KC, et al. Anti-CD3 monoclonal antibody 
in new-onset type 1 diabetes mellitus. $N$ Engl J Med. 2002;346(22):1692-1698.

6. Grunnet LG, et al. Proinflammatory cytokines activate the intrinsic apoptotic pathway in betacells. Diabetes. 2009;58(8):1807-1815.

7. Cnop M, Welsh N, Jonas JC, Jörns A, Lenzen S, Eizirik DL. Mechanisms of pancreatic beta-cell death in type 1 and type 2 diabetes: many differences, few similarities. Diabetes. 2005;54 Suppl 2:S97-107.

8. Atkinson MA, et al. How does type 1 diabetes develop?: the notion of homicide or $\beta$-cell suicide revisited. Diabetes. 2011;60(5):1370-1379.

9. Michalska M, Wolf G, Walther R, Newsholme P. Effects of pharmacological inhibition of NADPH oxidase or iNOS on pro-inflammatory cytokine, palmitic acid or $\mathrm{H} 2 \mathrm{O} 2$-induced mouse islet or clonal pancreatic $\beta$-cell dysfunction. Biosci Rep. 2010;30(6):445-453.

10. Veluthakal R, Sidarala V, Kowluru A. NSC23766, a known inhibitor of Tiam1-Rac1 signaling module, prevents the onset of type 1 diabetes in the NOD mouse model. Cell Physiol Biochem. 2016;39(2):760-767.

11. Lee Y, Hirose H, Ohneda M, Johnson JH, McGarry JD, Unger RH. Beta-cell lipotoxicity in the pathogenesis of non-insulin-dependent diabetes mellitus of obese rats: impairment in adipocyte-beta-cell relationships. Proc Natl Acad Sci USA. 1994;91(23):10878-10882.

12. Bach JF. Anti-CD3 antibodies for type 1 diabetes: beyond expectations. Lancet. 2011;378(9790):459-460.

13. Ludvigsson J, et al. GAD65 antigen therapy in recently diagnosed type 1 diabetes mellitus. N Engl J Med. 2012;366(5):433-442.

14. Shapiro AM, et al. Islet transplantation in seven patients with type 1 diabetes mellitus using a glucocorticoid-free immunosuppressive regimen. NEngl JMed. 2000;343(4):230-238.

15. Shapiro AM, et al. International trial of the Edmonton protocol for islet transplantation. N Engl J Med. 2006;355(13):1318-1330.

16. Buschard K, Diamant M, Bovin LE, Månsson JE, Fredman P, Bendtzen K. Sulphatide and its precursor galactosylceramide influence the production of cytokines in human mononuclear cells. APMIS. 1996;104(12):938-944.

17. Laychock SG, Sessanna SM, Lin MH, Mastrandrea LD. Sphingosine 1-phosphate affects cytokineinduced apoptosis in rat pancreatic islet beta-cells. Endocrinology. 2006;147(10):4705-4712.

18. Buschard K, Hanspers K, Fredman P, Reich EP. Treatment with sulfatide or its precursor, galactosylceramide, prevents diabetes in NOD mice. Autoimmunity. 2001;34(1):9-17.

19. Norris JM, et al. Omega-3 polyunsaturated fatty acid intake and islet autoimmunity in children at increased risk for type 1 diabetes. JAMA. 2007;298(12):1420-1428.

20. Wei D, et al. Cellular production of n-3 PUFAs and reduction of n-6-to-n-3 ratios in the pancreatic beta-cells and islets enhance insulin secretion and confer protection against cytokine-induced cell death. Diabetes. 2010;59(2):471-478.

21. Weylandt KH, Chiu CY, Gomolka B, Waechter SF, Wiedenmann B. Omega-3 fatty acids and their lipid mediators: towards an understanding of resolvin and protectin formation. Prostaglandins
Other Lipid Mediat. 2012;97(3-4):73-82.

22. Endres S, et al. The effect of dietary supplementation with $n-3$ polyunsaturated fatty acids on the synthesis of interleukin-1 and tumor necrosis factor by mononuclear cells. $N$ Engl J Med. 1989;320(5):265-271.

23. Bi X, et al. $\omega-3$ polyunsaturated fatty acids ameliorate type 1 diabetes and autoimmunity. JClin Invest. 2017;127(5):1757-1771.

24. Reed JC, Herold KC. Thinking bedside at the bench: the NOD mouse model of T1DM. Nat Rev Endocrinol. 2015;11(5):308-314.

25 . Yore MM, et al. Discovery of a class of endogenous mammalian lipids with anti-diabetic and antiinflammatory effects. Cell. 2014;159(2):318-332.

26. Kuda O, et al. Docosahexaenoic acid-derived fatty acid esters of hydroxy fatty acids (FAHFAs) with anti-inflammatory properties. Diabetes. 2016;65(9):2580-2590.

27. Ma Y, Kind T, Vaniya A, Gennity I, Fahrmann JF, Fiehn O. An in silico MS/MS library for automatic annotation of novel FAHFA lipids. JCheminform. 2015;7:53.

28. Lee J, et al. Branched fatty acid esters of hydroxy fatty acids (FAHFAs) protect against colitis by regulating gut innate and adaptive immune responses. J Biol Chem. 2016;291(42):22207-22217.

29. Fu W, et al. Epigenetic modulation of type-1 diabetes via a dual effect on pancreatic macrophages and $\beta$ cells. Elife. 2014;3:e04631.

30. Syed I, et al. Palmitic acid hydroxystearic acids activate GPR40, which is involved in their beneficial effects on glucose homeostasis. Cell Metab. 2018;27(2):419-427.e4.

31. Hadjiyanni I, Baggio LL, Poussier P, Drucker DJ. Exendin-4 modulates diabetes onset in nonobese diabetic mice. Endocrinology. 2008;149(3):1338-1349.

32. Cnop M, Toivonen S, Igoillo-Esteve M, Salpea P. Endoplasmic reticulum stress and eIF $2 \alpha$ phosphorylation: The Achilles heel of pancreatic $\beta$ cells. Mol Metab. 2017;6(9):1024-1039.

33. Veluthakal R, Jangati GR, Kowluru A. IL-1betainduced iNOS expression, NO release and loss in metabolic cell viability are resistant to inhibitors of ceramide synthase and sphingomyelinase in INS 832/13 cells. JOP. 2006;7(6):593-601.

34. Padgett LE, Broniowska KA, Hansen PA, Corbett JA, Tse HM. The role of reactive oxygen species and proinflammatory cytokines in type 1 diabetes pathogenesis. Ann N Y Acad Sci. 2013;1281:16-35.

35. Burke SJ, et al. IL-1 $\beta$ reciprocally regulates chemokine and insulin secretion in pancreatic $\beta$-cells via NF- $\kappa$ B. Am J Physiol Endocrinol Metab. 2015;309(8):E715-E726

36. Syed I, et al. Methodological issues in studying PAHSA Biology: masking PAHSA effects. Cell Metab. 2018;28(4):543-546.

37. Shepherd PR, Gnudi L, Tozzo E, Yang H, Leach F, Kahn BB. Adipose cell hyperplasia and enhanced glucose disposal in transgenic mice overexpressing GLUT4 selectively in adipose tissue. J Biol Chem. 1993;268(30):22243-22246.

38. Lehuen A, Diana J, Zaccone P, Cooke A. Immune cell crosstalk in type 1 diabetes. Nat Rev Immunol. 2010;10(7):501-513.

39. Charlton B, Lafferty KJ. The Th1/Th2 balance in autoimmunity. Curr Opin Immunol.
1995;7(6):793-798.

40. Delovitch TL, Singh B. The nonobese diabetic mouse as a model of autoimmune diabetes: immune dysregulation gets the NOD. Immunity. 1997;7(6):727-738.

41. Cambier JC, Gauld SB, Merrell KT, Vilen BJ. B-cell anergy: from transgenic models to naturally occurring anergic B cells? Nat Rev Immunol. 2007;7(8):633-643.

42. Roncarolo MG, Battaglia M. Regulatory T-cell immunotherapy for tolerance to self antigens and alloantigens in humans. Nat Rev Immunol. 2007;7(8):585-598.

43. Vija L, et al. Mesenchymal stem cells: Stem cell therapy perspectives for type 1 diabetes. Diabetes Metab. 2009;35(2):85-93.

44. Dai C, et al. Age-dependent human $\beta$ cell proliferation induced by glucagon-like peptide 1 and calcineurin signaling. JClin Invest. 2017;127(10):3835-3844.

45. Rankin MM, Kushner JA. Adaptive beta-cell proliferation is severely restricted with advanced age. Diabetes. 2009;58(6):1365-1372.

46. Kulkarni RN, Mizrachi EB, Ocana AG, Stewart AF. Human $\beta$-cell proliferation and intracellular signaling: driving in the dark without a road map. Diabetes. 2012;61(9):2205-2213.

47. Dor Y, Brown J, Martinez OI, Melton DA. Adult pancreatic beta-cells are formed by self-duplication rather than stem-cell differentiation. Nature. 2004;429(6987):41-46.

48. Kushner JA, Weir GC, Bonner-Weir S. Ductal origin hypothesis of pancreatic regeneration under attack. Cell Metab. 2010;11(1):2-3.

49. Xu X, et al. Beta cells can be generated from endogenous progenitors in injured adult mouse pancreas. Cell. 2008;132(2):197-207.

50. Minami K, et al. Lineage tracing and characterization of insulin-secreting cells generated from adult pancreatic acinar cells. Proc Natl Acad Sci USA. 2005;102(42):15116-15121.

51. Thorel F, et al. Conversion of adult pancreatic alpha-cells to beta-cells after extreme beta-cell loss. Nature. 2010;464(7292):1149-1154.

52. Brozzi F, Eizirik DL. ER stress and the decline and fall of pancreatic beta cells in type 1 diabetes. Ups JMed Sci. 2016;121(2):133-139.

53. Mokhtari D, Myers JW, Welsh N. The MAPK kinase kinase-1 is essential for stress-induced pancreatic islet cell death. Endocrinology. 2008;149(6):3046-3053.

54. Stene LC, Joner G, Norwegian Childhood Diabetes Study Group. Use of cod liver oil during the first year of life is associated with lower risk of childhood-onset type 1 diabetes: a large, population-based, case-control study. Am J Clin Nutr. 2003;78(6):1128-1134.

55. Chase HP, et al. Effect of docosahexaenoic acid supplementation on inflammatory cytokine levels in infants at high genetic risk for type 1 diabetes. Pediatr Diabetes. 2015;16(4):271-279.

56. Miller MR, et al. Erythrocyte membrane omega-3 fatty acid levels and omega- 3 fatty acid intake are not associated with conversion to type 1 diabetes in children with islet autoimmunity: the Diabetes Autoimmunity Study in the Young (DAISY). Pediatr Diabetes. 2011;12(8):669-675.

57. Yang W, et al. Fish oil supplementation inhibits 
endoplasmic reticulum stress and improves insulin resistance: involvement of AMP-activated protein kinase. Food Funct. 2017;8(4):1481-1493.

58. Kolar MJ, et al. Branched fatty acid esters of hydroxy fatty acids are preferred substrates of the MODY8 protein carboxyl ester lipase. Biochemistry. 2016;55(33):4636-4641.

59. Parsons WH, et al. AIG1 and ADTRP are atypical integral membrane hydrolases that degrade bioactive FAHFAs. Nat Chem Biol. 2016;12(5):367-372.

60. Raeder $\mathrm{H}$, et al. Mutations in the CEL VNTR cause a syndrome of diabetes and pancreatic exocrine dysfunction. Nat Genet. 2006;38(1):54-62.

61. Pflimlin E, et al. Acute and repeated treatment with 5-PAHSA or 9-PAHSA isomers does not improve glucose control in mice. Cell Metab. 2018;28(2):217-227.e13.
62. Kuda O. On the Complexity of PAHSA Research. Cell Metab. 2018;28(4):541-542.

63. Bandak B, Yi L, Roper MG. Microfluidic-enabled quantitative measurements of insulin release dynamics from single islets of Langerhans in response to 5-palmitic acid hydroxy stearic acid. Lab Chip. 2018;18(18):2873-2882.

64. Mestas J, Hughes CC. Of mice and not men: differences between mouse and human immunology. JImmunol. 2004;172(5):2731-2738.

65. Makino S, Kunimoto K, Muraoka Y, Mizushima $\mathrm{Y}$, Katagiri K, Tochino Y. Breeding of a nonobese, diabetic strain of mice. Jikken Dobutsu. 1980;29(1):1-13.

66. Pearson JA, Wong FS, Wen L. The importance of the non-obese diabetic (NOD) mouse model in autoimmune diabetes. JAutoimmun. 2016;66:76-88.
67. Nelson AT, et al. Stereochemistry of endogenous palmitic acid ester of 9-hydroxystearic acid and relevance of absolute configuration to regulation. JAm Chem Soc. 2017;139(13):4943-4947.

68. Kowluru A, Veluthakal R, Rhodes CJ, Kamath V, Syed I, Koch BJ. Protein farnesylation-dependent Raf/extracellular signal-related kinase signaling links to cytoskeletal remodeling to facilitate glucose-induced insulin secretion in pancreatic beta-cells. Diabetes. 2010;59(4):967-977.

69. Zhang T, et al. A LC-MS-based workflow for measurement of branched fatty acid esters of hydroxy fatty acids. Nat Protoc. 2016;11(4):747-763.

70. Vijayakumar A, et al. Absence of carbohydrate response element binding protein in adipocytes causes systemic insulin resistance and impairs glucose transport. Cell Rep. 2017;21(4):1021-1035. 